University of South Florida

DIGITAL COMMONS

Digital Commons @ University of

@ UNIVERSITY OF SOUTH FLORIDA

South Florida

6-12-2003

\title{
Local and Deep-Ocean Forcing Contributions to Anomalous Water Properties on the West Florida Shelf
}

\author{
Robert H. Weisberg \\ University of South Florida, weisberg@usf.edu \\ Ruoying $\mathrm{He}$ \\ University of South Florida
}

Follow this and additional works at: https://digitalcommons.usf.edu/msc_facpub

Part of the Marine Biology Commons

\section{Scholar Commons Citation}

Weisberg, Robert H. and He, Ruoying, "Local and Deep-Ocean Forcing Contributions to Anomalous Water Properties on the West Florida Shelf" (2003). Marine Science Faculty Publications. 129.

https://digitalcommons.usf.edu/msc_facpub/129

This Article is brought to you for free and open access by the College of Marine Science at Digital Commons @ University of South Florida. It has been accepted for inclusion in Marine Science Faculty Publications by an authorized administrator of Digital Commons @ University of South Florida. For more information, please contact digitalcommons@usf.edu. 


\title{
Local and deep-ocean forcing contributions to anomalous water properties on the West Florida Shelf
}

\author{
Robert H. Weisberg and Ruoying He \\ College of Marine Science, University of South Florida, St. Petersburg, Florida, USA
}

Received 25 March 2002; revised 4 December 2002; accepted 25 February 2003; published 12 June 2003.

[1] Material property distributions on continental shelves result from the mixing and modifications of estuarine and deep-ocean source waters. How this occurs depends on the momentum and buoyancy that are input either locally on the shelf or from the deep-ocean at the shelf break. We address this question of local versus deep-ocean forcing for the West Florida Shelf (WFS) using in situ data and a numerical circulation model. The spring and summer seasons of 1998 and 1999 show distinctively different water properties on the shelf and at the shelf break. We account for these differences by a combination of local forcing, independent of the adjacent Gulf of Mexico Loop Current, and interactions of the Loop Current with the shelf. The primary role of the deep ocean is to set the height of material isopleths along the shelf slope. Whether or not these material isopleths broach the shelf break is then a consequence of local, shelf-wide wind and buoyancy forcing. The subsequent along- and across-shelf distributions are accomplished through a combination of local and deep-ocean effects, with the bottom Ekman layer being the major conduit for the across-shelf transport of ecologically important materials. INDEX TERMS: 4219 Oceanography: General: Continental shelf processes; 4512 Oceanography: Physical: Currents; 4255 Oceanography: General: Numerical modeling; KEYWORDS: West Florida Shelf, circulation, modeling, observations

Citation: Weisberg, R. H., and R. He, Local and deep-ocean forcing contributions to anomalous water properties on the West Florida Shelf, J. Geophys. Res., 108(C6), 3184, doi:10.1029/2002JC001407, 2003.

\section{Introduction}

[2] Continental shelves are buffer regions between the coast and the deep ocean. There, estuarine and ocean waters are mixed and modified to determine the material properties of the shelf. How this occurs depends on local and deepocean forcing effects. Here we define local forcing as the shelf-wide inputs of momentum (by winds) and buoyancy (by surface heat and fresh water fluxes and river inflows), and deep-ocean forcing as the inputs of momentum and buoyancy by currents at the shelf break.

[3] The West Florida Shelf (WFS), for our purposes, extends from the Florida Keys to the Mississippi River (Figure 1). It is influenced by the Gulf of Mexico Loop Current (LC), which enters through the Yucatan Channel and exits as the Gulf Stream through the Florida Straits. While en route the LC migrates northward and sheds an anticyclonic eddy before collapsing back and starting its northward migration anew [e.g., Sturges and Leben, 2000]. At times the LC and its eddies impinge on the WFS, and, at the very least, their baroclinic structure sets the thermocline height at the shelf slope and hence the potential for driving cold, nutrient rich waters onto the shelf. Whether the LC drives water onto the shelf or merely sets the stage from which local processes take over is the main question of our paper. General reviews on the effects of local wind, buoy-

Copyright 2003 by the American Geophysical Union. 0148-0227/03/2002JC001407 ancy, and deep-ocean forcing on continental shelves are provided by Brink [1998a], Hill [1998], and Brink [1998b], respectively, and Boicourt et al. [1998] shows that distinguishing these effects remains challenging.

[4] The WFS is wide and gently sloping in the south where it is partially closed by the Florida Keys. It remains wide with subtle variations northward. It then narrows west of Cape San Blas on the Florida Panhandle where it pinches down to a minimum at DeSoto Canyon. The shelf then widens again in the Mississippi Bight before hitting a choke point at the Mississippi River delta. Local forcing throughout the WFS is by seasonal and synoptic-scale weather systems, tropical cyclones, and distributed river inputs. The Mississippi River is the major fresh water source. East of the Mississippi are the cumulative inputs from other rivers of southeast USA origin and the inflows from Florida's estuaries and the Everglades. These river inputs vary seasonally with peak flows in spring for the rivers entering the northern portion of the domain and in summer for the rivers originating in Florida. In sum, the WFS provides an excellent natural laboratory for continental shelf process studies. It contains both topographic end members: regions of wide, gently sloping and narrow, steeply sloping isobaths; it has an adjacent boundary current; and it is meteorologically forced by well-defined seasons with positive and negative surface heat fluxes and modulated synoptic-scale winds.

[5] WFS measurements suggest a seasonal cycle in which the circulation tends toward upwelling in winter and down- 


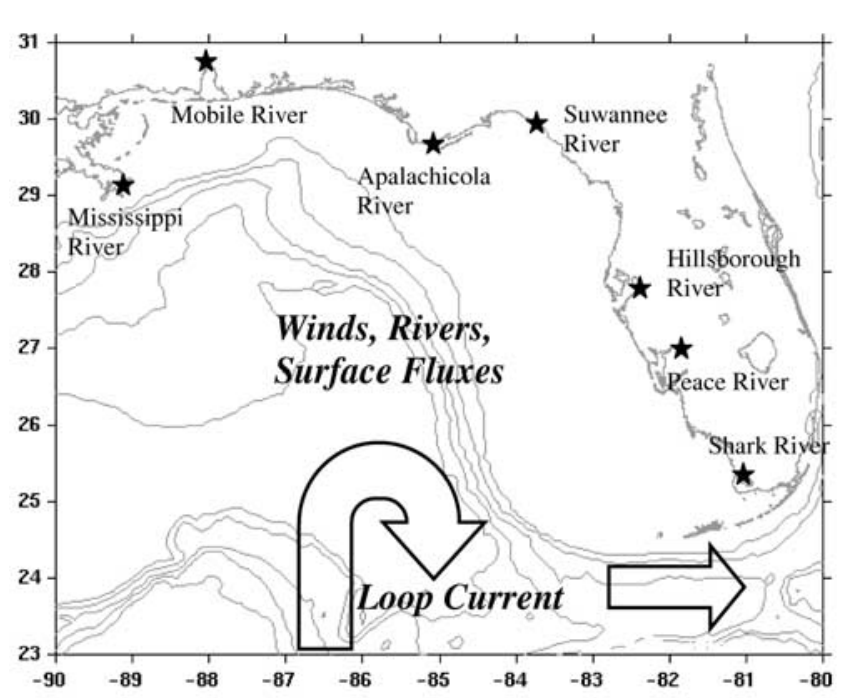

Figure 1. Local and offshore forcing influences for the West Florida Shelf.

welling in summer, consistent with the wind stress climatology [Yang and Weisberg, 1999]. Spring and fall transitions begin when the net surface heat flux changes sign. Weisberg et al. [1996] hypothesize that baroclinicity imposed by surface heat flux is a necessary part of the seasonal circulation, and this hypothesis is borne out by the data and model analyses of He and Weisberg [2002a, 2003a] for spring and fall, respectively. Not all years are alike, however. In 1998 the shelf water stayed anomalously cold well into summer and with a sharply defined thermocline that intercepted the beach. Can such interannual behavior be accounted for by local forcing, or must deep-ocean influence be invoked, and, if so, how? Such behaviors are also important biologically.
The WFS is an epicenter for $K$. brevis red tide [e.g., Steidinger et al., 1998], and while the WFS is considered to be oligotrophic it supports major recreational and commercial fisheries. Unraveling the circulation influences on material property distributions is necessary for understanding these ecological consequences.

[6] Our paper is organized as follows. Currents and hydrography from 1998 and 1999 are described in section 2. Model simulation under local forcing explains some of the observed differences in section 3. Local forcing cannot account for all of the 1998 anomalies, however. On the basis of anomalous sea surface height gradients observed near the Florida Keys and the Hetland et al. [1999] hypothesis that LC impacts there affect the WFS because of isobath convergence, an idealized LC is added to the model simulation in section 4 to account for the remaining anomalies. Section 5 discusses the results, and how the interaction between local and deep-ocean forcing injects and transports cold, nutrientrich water onto and across the shelf. Section 6 is a summary.

\section{Observations}

[7] Spring through fall of 1998 shows anomalous stratification and coastal upwelling. Anomalous is qualified as anecdotal since WFS data are insufficient to define deviations from climatologies. Nevertheless, sea surface temperature (SST) by satellite imagery was colder than normal along the west Florida coastline, hot summer bathers rejoiced to rivulets of cold water welling up at their feet, and recreational divers carped about cold, murky water below a sharp, shallow thermocline.

[8] Measurements from the Ecology and Oceanography of Harmful Algae Blooms (ECOHAB: Florida) Program began in June 1998, prior to which we have a more limited data set. Figure 2 shows the positions of available

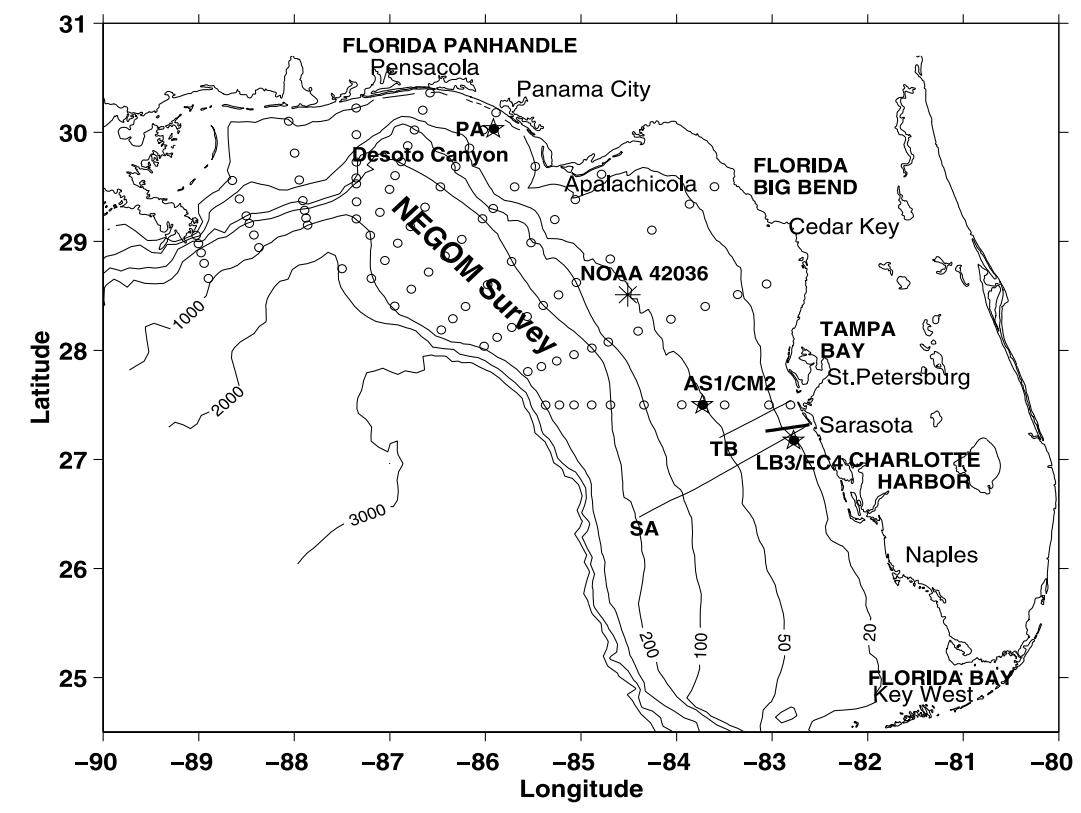

Figure 2. Hydrographic and current measurement locations. Circles denote the Texas A\&M NEGOM stations. Thin and thick lines denote the USF Tampa (TB) and Sarasota (SA) and the Mote hydrographic transects, respectively. The asterisk denotes NOAA buoy 42036. Stars denote moored ADCP sites at the $30 \mathrm{~m}$ (PA) isobath by FSU and at the $50 \mathrm{~m}(\mathrm{AS} 1 / \mathrm{CM} 2)$ and $20 \mathrm{~m}$ (LB3/EC4) isobaths by USF. 

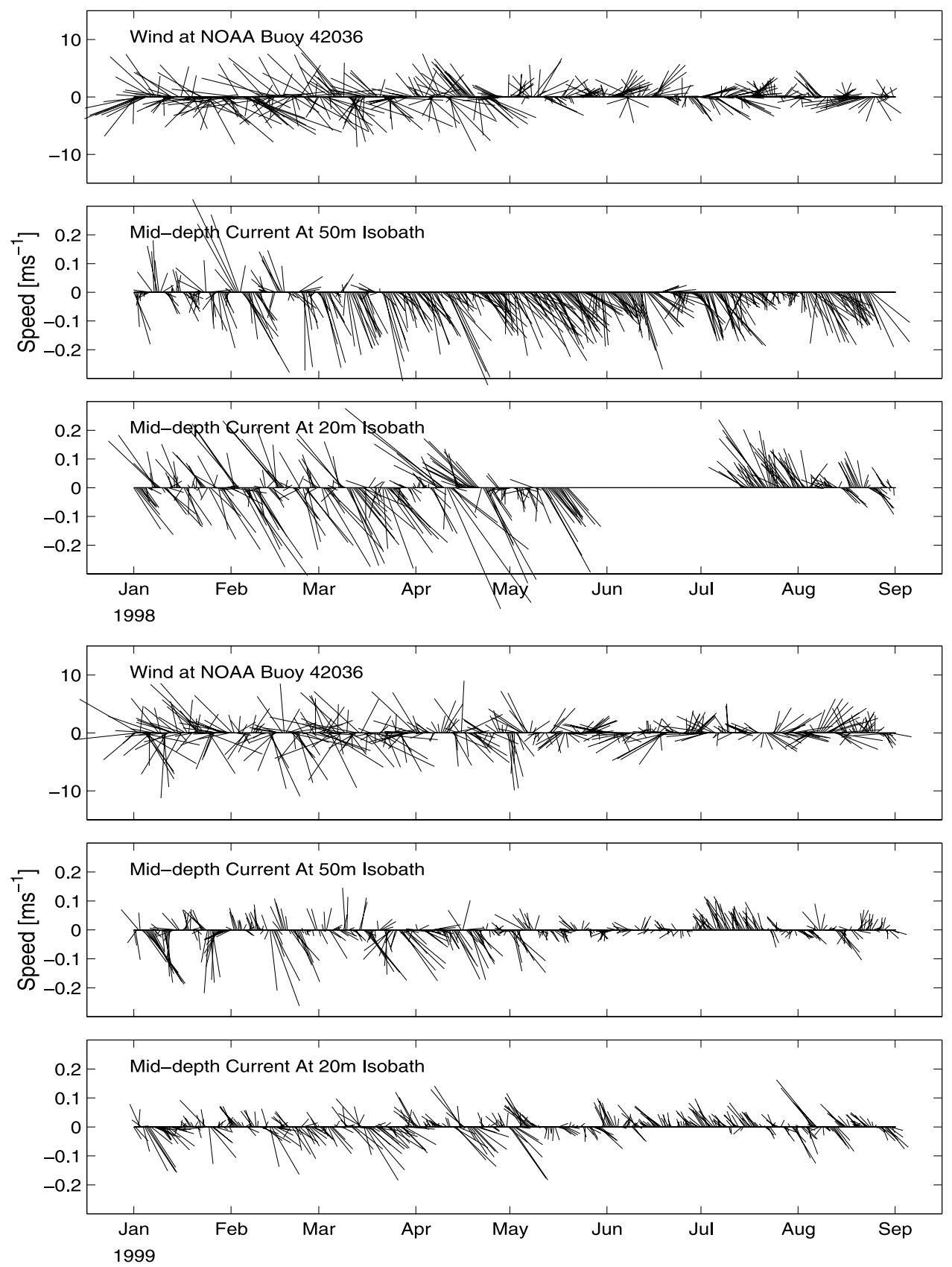

Figure 3. Time series of NOAA buoy winds, AS1/CM2 middepth currents (50 $\mathrm{m}$ isobath), and LB3/ EC4 middepth currents (20 m isobath) from January to September 1998 (upper three panels) and 1999 (lower three panels), all sampled daily after low-pass filtering to remove oscillations at timescales shorter than 36 hours.

time series and hydrographic sections. We begin with wind velocity vectors from NOAA buoy 42036 and water velocity vectors from moorings at the $50 \mathrm{~m}$ and $20 \mathrm{~m}$ isobaths. These are compared for January-September of 1998 and 1999 in Figure 3. Synoptic-scale wind variability in both years is largest in winter and smallest in summer, but the wind vectors are larger, and the durations over which these winds are upwelling favorable are longer in 1998 than in 1999. Beginning in May 1998 there is an approximate 2-month period in which the winds tend to be upwelling favorable along the northern Florida Panhandle with no counterpart in 1999. The currents are also different. During the first two months of 1998 the currents at the $50 \mathrm{~m}$ isobath tend to fluctuate with the winds, whereas they change in March to become more unidirectional toward the southeast for the remainder of the record. No such behavior is seen in 1999. While there is a tendency in spring for southeast flow by local winds and surface heat flux [He and Weisberg, 2002a] (hereinafter referred to as HW02), both the magnitude and duration of these spring transition southeast currents in 1998 are different than in 1999. The $20 \mathrm{~m}$ isobath currents also show different 

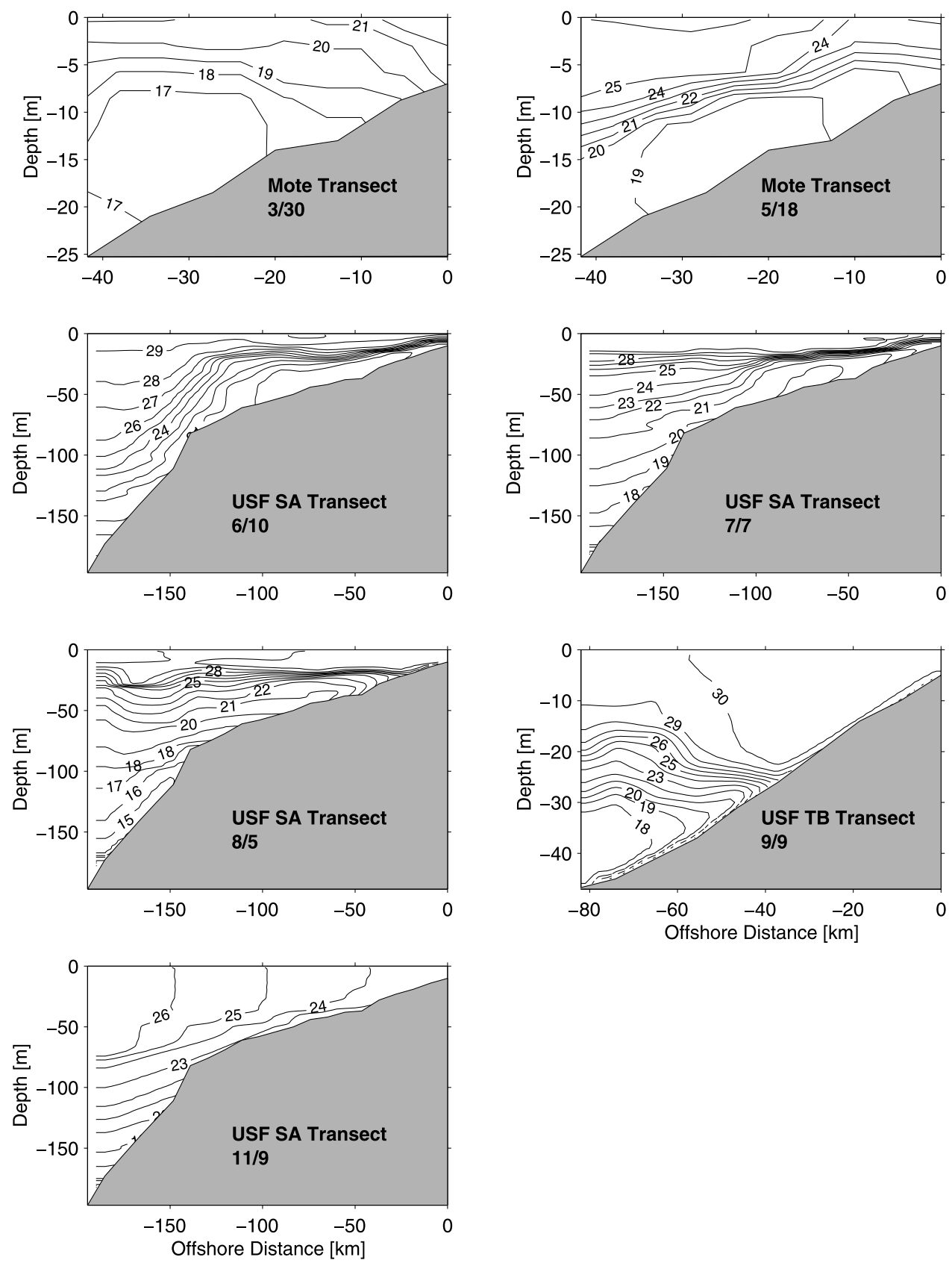

Figure 4. Mote Marine Lab (30 March and 18 May) and USF (10 June (SA); 7 July (SA), 5 August (SA), 9 September (TA), and 9 November (SA)) across-shelf temperature sections.

behaviors between these two years. They are generally stronger in 1998 than in 1999, May 1998 shows unidirectional currents in opposition to the winds, and the summertime currents remain strong. Water velocity vectors available at the $30 \mathrm{~m}$ isobath offshore of Panama City in the Florida Panhandle also show a unidirectional tendency from May to August 1998 in the same sense as the flow at the $50 \mathrm{~m}$ isobath farther south.

[9] The hydrography also differs between these two years. HW02 chose 1999 for their study of local forcing effects on the spring transition because the isotherms seaward of the shelf break were relatively flat. 1998 is different. Figure 4 provides temperature sections sampled offshore of Sarasota on 30 March, 18 May, 10 June, 7 July,
5 August, 9 September, and 9 November. The first four show thermoclines that intercept the beach. The offshore structure is seen in June, when steeply sloping isotherms occur at the shelf break. The thermocline persists over the innershelf in July, when the coldest waters there are separated from similar temperature waters seaward of the shelf break. We surmise that these cold, inner shelf waters originate farther north. It is not until August that typical summer conditions appear on the inner shelf. A relatively shallow thermocline persists into September, and November shows remnants of thermal stratification even in late fall. With monthly cruises available over three successive years we contend that the hydrography for spring through fall 1998 (like the currents) is different from what may be 
1998

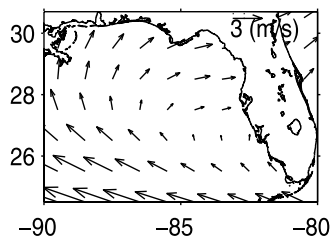

1999

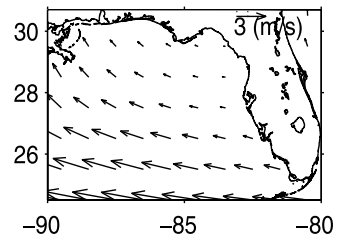

Climatology

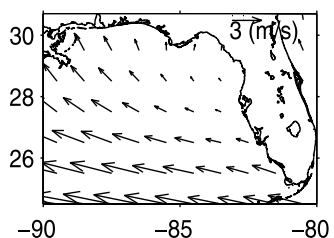

Figure 5. Spring season average (March-May) wind fields for 1998, 1999, and climatology.

considered normal. How can we reconcile these differences, and what are the implications?

\section{Model Simulation With Local Forcing Only \\ 3.1. Motivation}

[10] Anomalous winds motivate an analysis of local forcing effects, independent of the LC. Using the National Center for Environmental Predication (NCEP) reanalysis, Figure 5 compares spring season (March-May) average wind fields for 1998, 1999, and climatology. 1998 shows southwesterly, upwelling favorable winds [also see MullerKarger, 2000] along the northern portion of the shelf that differ from 1999 and climatology. This anomalous behavior results from the larger magnitude and longer lasting periods of upwelling favorable winds in 1998 relative to 1999 (Figure 3).

\subsection{Model and Forcing Fields}

[11] The model approach follows HW02. The primitive equation, Princeton Ocean Model (POM) [Blumberg and Mellor, 1987] is forced by NCEP reanalysis winds, net surface heat fluxes, and river inflows. The only role of the adjacent Gulf of Mexico is to set the vertical distribution of temperature and salinity for model initialization. Once begun, the integration proceeds solely on the basis of local forcing.

[12] The model domain (Figure 6) extends from the Florida Keys to the Mississippi River with one open boundary arcing between where a radiation condition [Orlanski, 1976] is applied. Seven major rivers are input using the technique of Kourafalou et al. [1996]. Horizontal resolution on an orthogonal curvilinear grid varies from 2 $\mathrm{km}$ nearshore to $6 \mathrm{~km}$ at the open boundary, and the vertical is resolved with a 21-layer sigma coordinate. Horizontal (vertical) diffusivities are parameterized following Smagorinsky [1963] with a coefficient of 0.2 [Mellor and Yamada, 1982], and bottom stress follows a quadratic drag law with a variable coefficient of minimum value 0.0025 . Time steps of $6 \mathrm{~s}$ and $360 \mathrm{~s}$ are respectively employed for the model external and internal modes.

[13] The model begins at rest on 28 February 1998, initialized with the same uniform stratification as in HW02 (based on climatology below and a March 1999 hydrographic survey above $200 \mathrm{~m}$ ). Any deviations from the HW02 spring 1999 results must therefore be a consequence of local forcing changes since everything else is identical. From this initial state, the model spins up rapidly, generating baroclinicity in balance with the local wind and buoyancy forcing. Tides are excluded since tidal currents, with magnitudes of only a few $\mathrm{cm} \mathrm{s}^{-1}$, are not essential contributors to vertical mixing over most of the WFS. A comparison between modeled and observed tidal currents and their mixing efficacy are given by He and Weisberg [2002b].

[14] The wind and heat flux forcing fields begin with the NCEP daily reanalysis interpolated onto the model grid. Comparisons between the NCEP winds and observations are generally good (the buoy winds are included in the NCEP reanalysis). An exception is at Venice (midway between Tampa Bay and Charlotte Harbor) where the NCEP wind speeds from mid-April to early August underrepresent the Venice wind speeds by about a factor of two. This discrepancy, occurring when SST is anomalously cold along the coast, is observed elsewhere [e.g., Baumgartner and Anderson, 1999]. To correct for it we spatially ramp the wind speed up by a factor of two for the region between Tampa Bay and Charlotte Harbor and offshore to about the $50 \mathrm{~m}$ isobath. Heat flux forcing is also modified to account for SST features unresolved by the coarse NCEP fields. We add a correction term [e.g., Ezer and Mellor, 1992; Chu et al., 1999] that tends to relax the model SST to an interpolated product of satellite monthly mean SST.

\subsection{Results}

[15] The modeled end of spring (May 31) states for 1998 and 1999 (Figure 7) demonstrate that local forcing can account for interannual variations in WFS circulation and water properties. The top (spring 1999) and middle (spring 1998) panels show the currents to be larger and displaced farther offshore in 1998 than in 1999. As a consequence, low-salinity water (of Mississippi River origin) is transported farther south in 1998, independent of the LC.

[16] Quantitative comparisons between modeled and observed currents at the 50,20, and $30 \mathrm{~m}$ isobaths for March-

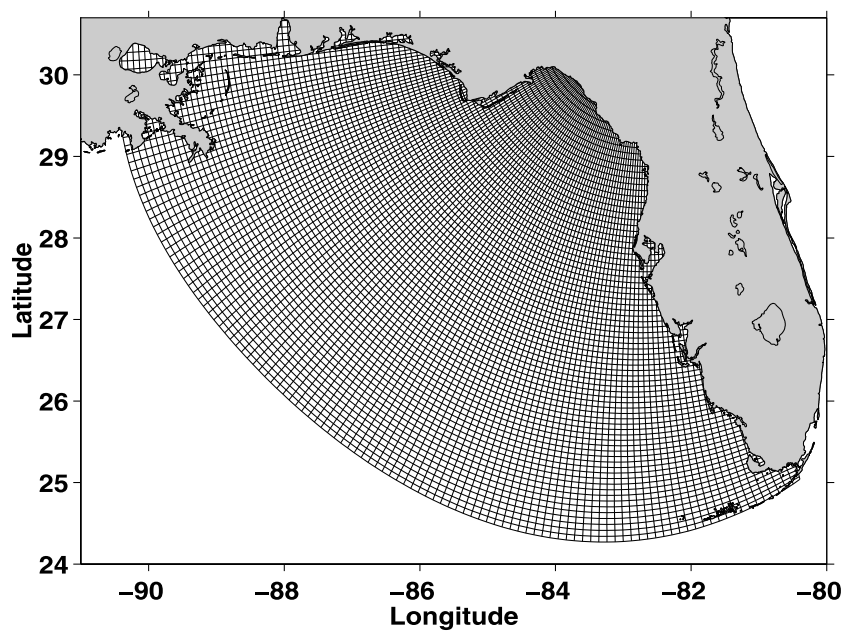

Figure 6. West Florida Shelf model domain. 

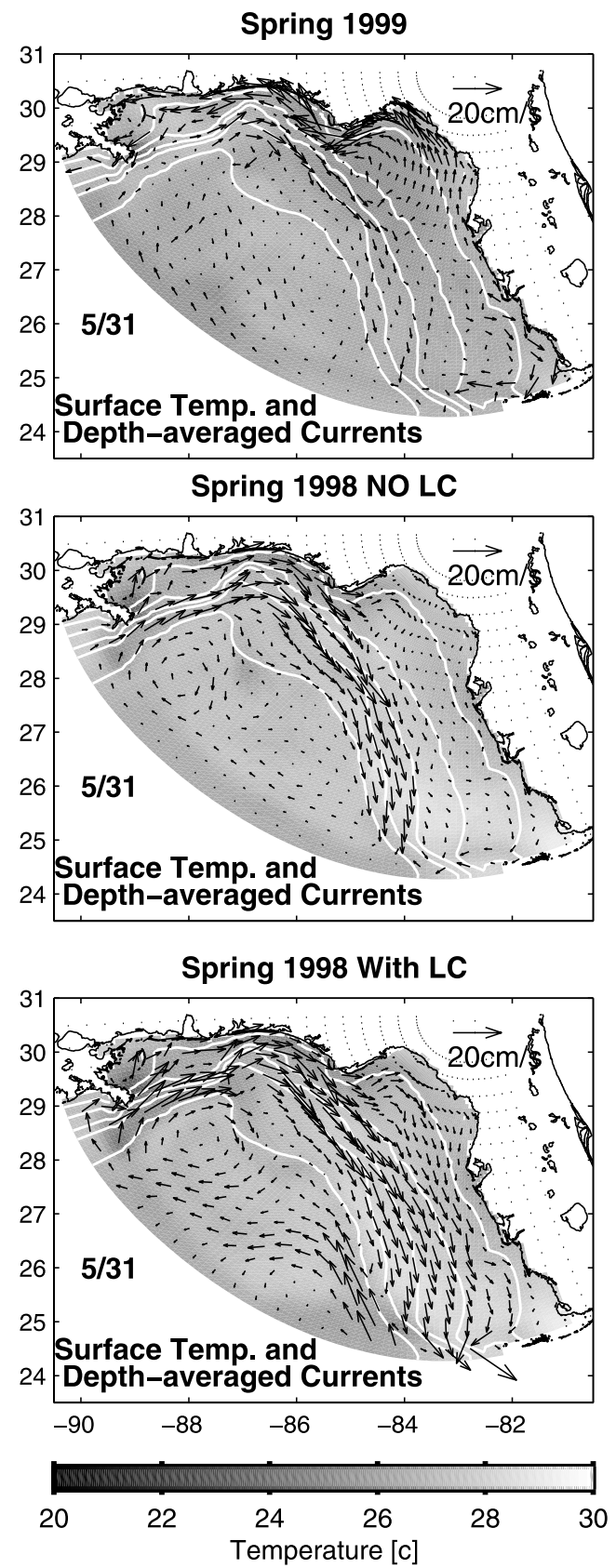
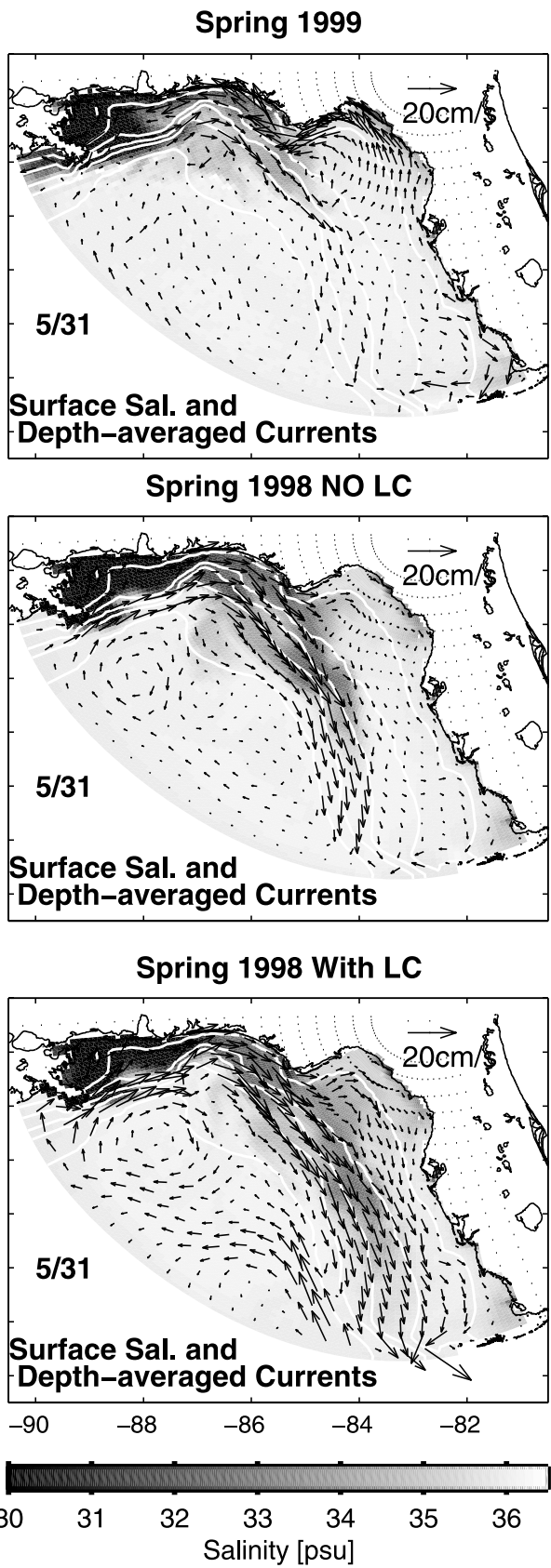

Figure 7. Modeled depth-averaged currents superimposed on (left) modeled sea surface temperature and (right) sea surface salinity sampled at the end of the spring runs on 31 May. (top) The spring 1999 case under local forcing only. (middle) The spring 1998 case under local forcing only. (bottom) The spring 1998 case under local plus LC forcing.

August 1998 are given in Figures 8a, 9a, and 10a, respectively. Included with each near-surface, middepth, and nearbottom time series are record length velocity component means and with each model/data time series pair are vector correlation coefficients, orientation differences, and regression coefficients. The $50 \mathrm{~m}$ site shows some agreement during the first three synoptic weather cycles, but departures appear at the end of March when the modeled currents oscillate with the winds, whereas the observed currents are more unidirectional. Model failure is most evident at depth. Near the surface, the model and data tendencies are similar, although the magnitudes are different. The $20 \mathrm{~m}$ site also shows something amiss. The model and data generally agree through the end of April [Weisberg et al., 2001], but the data then tend southward in opposition to the wind, whereas the modeled currents tend northward with the wind. In July and August, the model and data again covary, but with a northward tendency opposite to that at the $50 \mathrm{~m}$ isobath.

[17] In the Florida Panhandle offshore of Panama City at the $30 \mathrm{~m}$ isobath we see better model/data agreement throughout the record (Figure 10a), including the period of unidirectional tendency from May through mid-July. Moreover, the temperature and velocity fields observed over the northern half of the study region by ship survey between 
(a) Local Forcing only

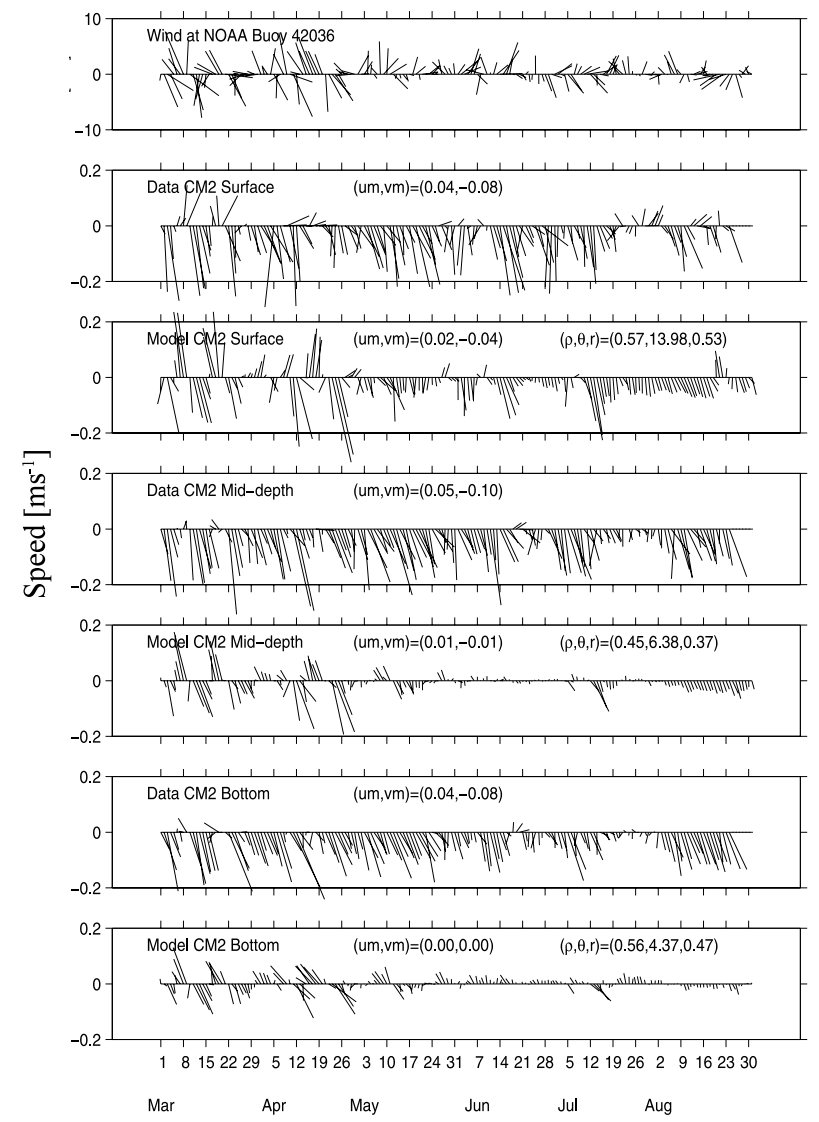

(b) Local + LC forcing

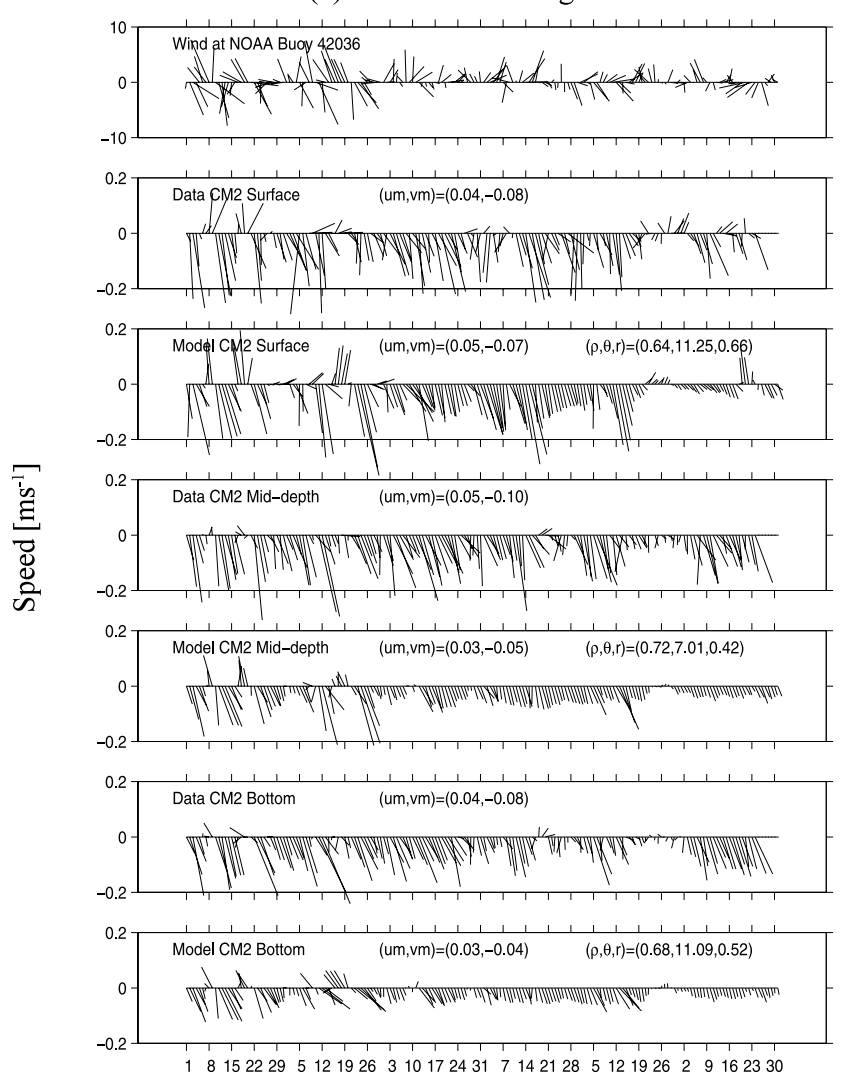

Mar Apr May Jun Jul Aug

Figure 8. Comparisons between observed and modeled currents at the $50 \mathrm{~m}$ isobath (AS1/CM2) sampled near the surface, at middepth, and near the bottom from March through August 1998 for the cases of (a) local forcing only and (b) local, plus LC forcing, along with the NOAA buoy 42036 winds. The vector time series are sampled daily after low-pass filtering to remove oscillations at timescales shorter than 36 hours. East and north are oriented to the right and up, respectively. Each current time series panel includes east and north component means (um and vm), and each observed and modeled current time series pair includes vector correlation coefficient, angular deviation, and regression coefficient $(\rho, \theta, r)$.

5 and 16 May [Nowlin et al., 1998, 2000] tend to agree with the model fields sampled on 10 May. The modeled (Figure 11) bottom temperature pattern shows upwelling at DeSoto Canyon and relatively cold water penetrating onto the shelf in the Big Bend, but with the modeled bottom temperatures about $1{ }^{\circ} \mathrm{C}$ warmer than observed. The modeled (Figure 12) velocity fields sampled at $14 \mathrm{~m}$ (the uppermost bin sampled by ship) and $50 \mathrm{~m}$ are more coherent than the observations since they are instantaneous, whereas the ship survey is sampled over 11 days. Two findings are notable. First, the modeled currents offshore of Tampa Bay nearest the coast flow north, whereas the currents farther offshore flow south. Given this across-shelf gradient, a small shoreward shift in the current field would increase the magnitude of the modeled currents at the $50 \mathrm{~m}$ isobath to be in better agreement with the moored observations (Figure 8a). Since the nature of the spatial distributions includes baroclinicity, it is important to get the density field correct in order to get the modeled currents correct. From this we surmise that local forcing alone did not produce the baroclinic structure well enough. Second, note the eddy in DeSoto Canyon, particu- larly at the $50 \mathrm{~m}$ depth. Such eddies are often attributed to the LC. Here we see that the canyon itself, via potential vorticity conservation, can generate its own eddy, independent of the LC. As fluid attempts to navigate the right angle bend in topography it flows uphill inducing negative relative vorticity and a clockwise eddy.

[18] Discrepancies notwithstanding, the temperature and velocity field comparisons over the northern portion of the domain show that the modeled patterns (in response to local forcing only) are generally correct. To see why this is true and to draw contrast with 1999, it is instructive to look at a particular synoptic-scale event. Consider the upwelling/downwelling sequence beginning on $10 \mathrm{March}$, a time by which the initial temperature distribution is adjusted to the surface fluxes. Figures 13 shows across-shelf sections for temperature and velocity at the DeSoto Canyon, where the shelf is narrowest. 10 March begins the transition from the preceding downwelling. We see onshore flow at all depths and an accelerating eastward coastal jet. By 12 March the coastal jet peaks, strong onshore flow continues at the shelf break, and deep waters of $18^{\circ}-19^{\circ} \mathrm{C}$ temperature are 
(a) Local Forcing only

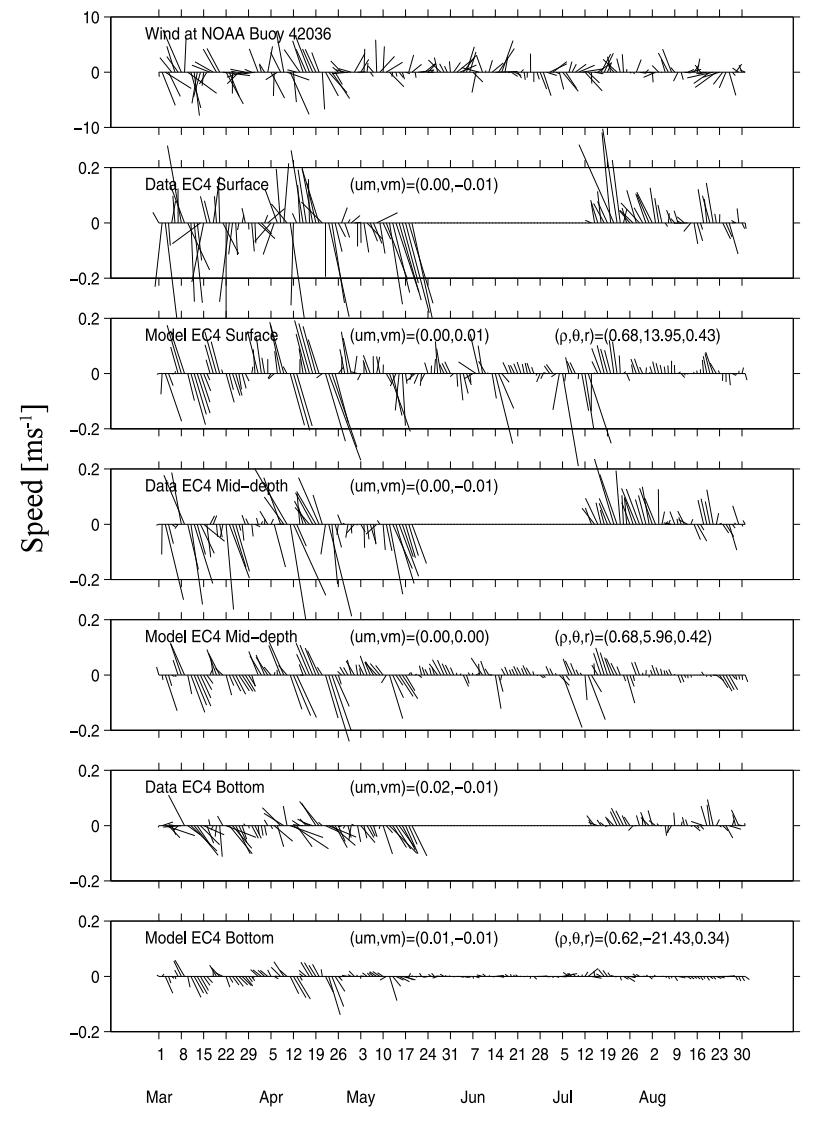

(b) Local + LC forcing

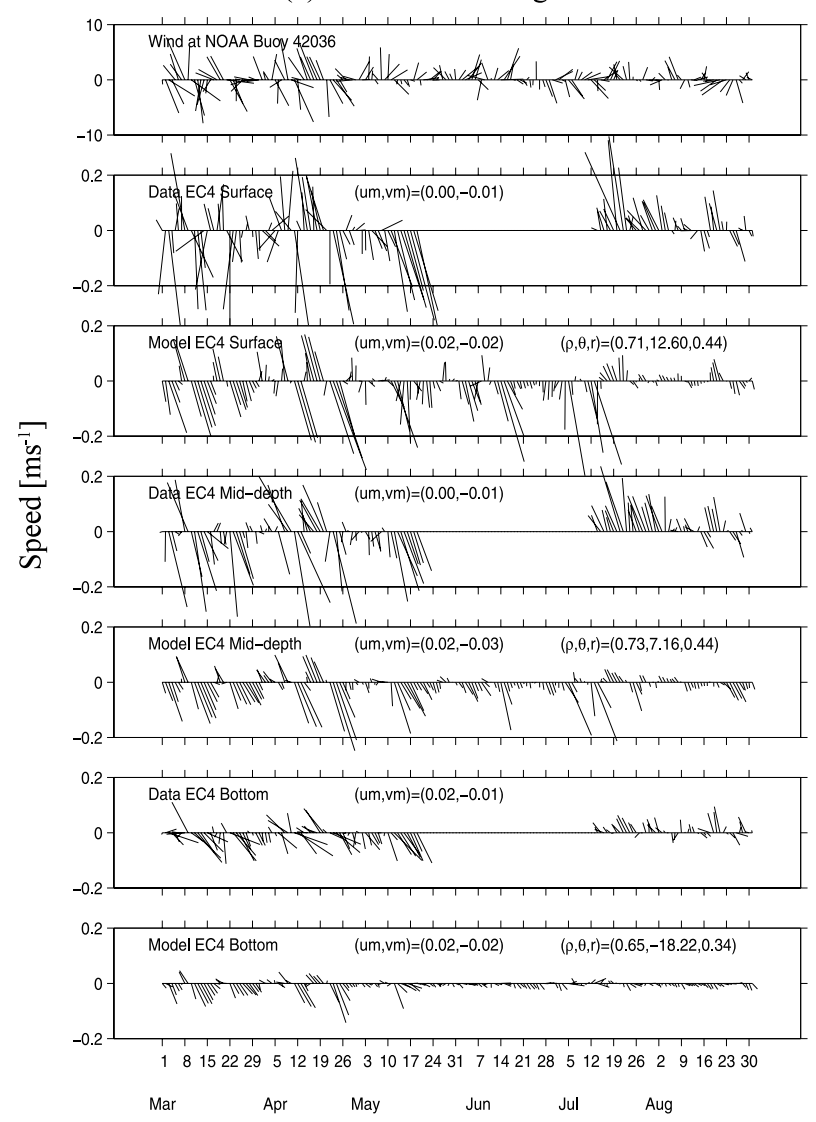

Figure 9. Same as Figure 8 except for observed and modeled currents at the $20 \mathrm{~m}$ isobath (LB3/EC4).

upwelled onto the shelf. Upwelling continues, and by 14 March the entire DeSoto Canyon shelf is in the range of $18^{\circ}-$ $19^{\circ} \mathrm{C}$ and waters of $17^{\circ}-18^{\circ} \mathrm{C}$ are broaching the shelf break, seaward of which the isotherms slope down to their initialized depths. Downwelling then commences, peaking on 19 March, while the nearshore temperatures remain cold by surface heat flux and along-shore advection. In contrast with this spring 1998 event, similar sequences for spring 1999 show no upwelling events of sufficient magnitude or duration to bring waters colder than $19^{\circ}-20^{\circ} \mathrm{C}$ onto the shelf. Thus the subtle changes in upwelling favorable wind magnitude and duration between spring 1998 and 1999 account for the markedly colder temperatures observed along the Florida Panhandle in 1998.

[19] Surface heat flux also contributes to SST. The Big Bend, where the shelf is widest, is the primary manufacturing site for cold water of shallow origin. Thus $18^{\circ} \mathrm{C}$ water is already present nearshore in the Big Bend prior to upwelling commencement, and these coldest nearshore waters remain separated from the waters upwelled at the shelf break (as demonstrated by a Cape San Blas section located between the DeSoto Canyon and Big Bend). Two sources of cold water therefore exist: a deep source by upwelling and a shallow source by surface heat flux. Waters found within the WFS cold tongue later in spring and summer result from a mixture of these two sources. The nutrient content is also a mixture of deep-ocean and estuarine sources. Thus the appearance of cold water by itself is neither indicative of upwelling, nor of high productivity potential.
[20] Farther south the ECOHAB hydrographic sections (Figure 4) show that local forcing alone does not account for the thermal structure. The model fails to account for stratification in March and April, and in May the stratification is too weak and the bottom temperature is too warm (Figure 14).

\section{Model Simulation With Local and Idealized LC Forcing}

\subsection{Motivation}

[21] The Florida Keys result in a convergence of isobaths west of the Dry Tortugas. Hetland et al. [1999] hypothesize that LC impacts at the shelf break there can set the shelf waters in motion by influencing relatively shallow isobaths; this being in contrast with LC impacts farther north where shallow isobaths are distant from the shelf break. Velocity data from a 1995 across-shelf moored array neither supports, nor rejects this hypothesis [Meyers et al., 2001]. Three LC impacts are observed, but none occurring sufficiently far south. He and Weisberg [2003b] describe a LC impact offshore of Sarasota in June 2000. Currents on the shelf break by the LC and currents on the innershelf by the winds are observed and modeled to be independent.

[22] A decade of TOPEX/Poseidon (T/P) altimetry data (Figure 15) offers clarification. Both the 1995 and 2000 observational periods are absent large sea level gradient anomalies over the southern WFS. Only four southwest 
(a) Local Forcing only

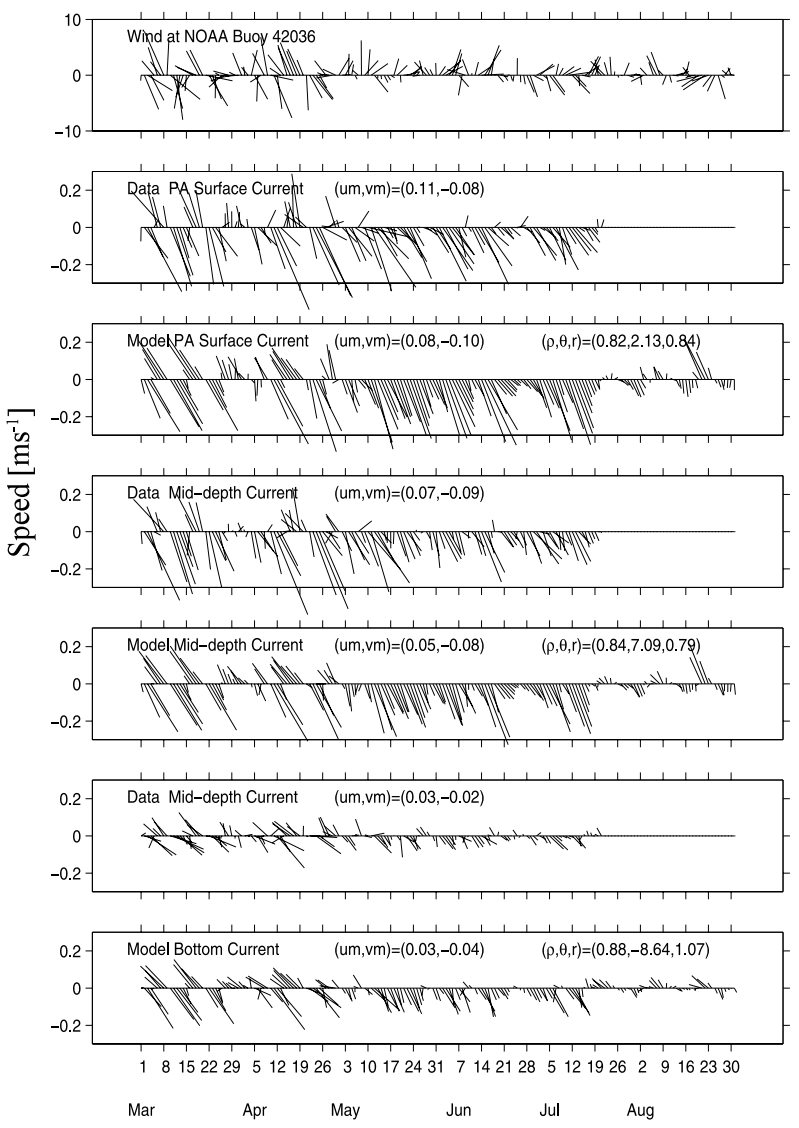

(b) Local + LC forcing
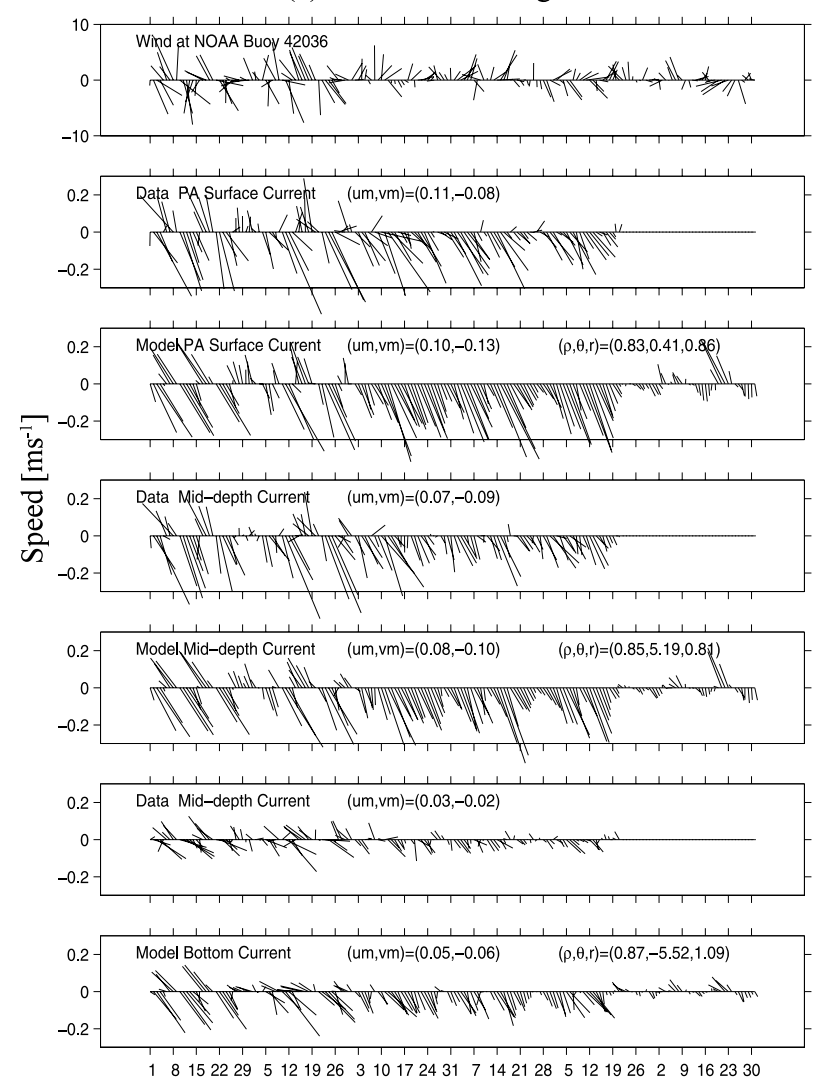

Mar Apr May Jun Jul Aug

Figure 10. Same as Figure 8 except for observed and modeled currents at the $30 \mathrm{~m}$ isobath (PA).

corner impact events stand out strongly over the record: October 1996 to March 1997, August 1997 to November 1997, March 1998 to July 1998, and September 1998 to December 1998, the third one of which corresponds to the analysis period here.

\subsection{Model and Forcing Fields}

[23] The technique of He and Weisberg [2003b] is used to assess the LC's influence on the WFS during the springsummer of 1998. Using the same initialization and wind and buoyancy forcing as in section 3, we control the surface

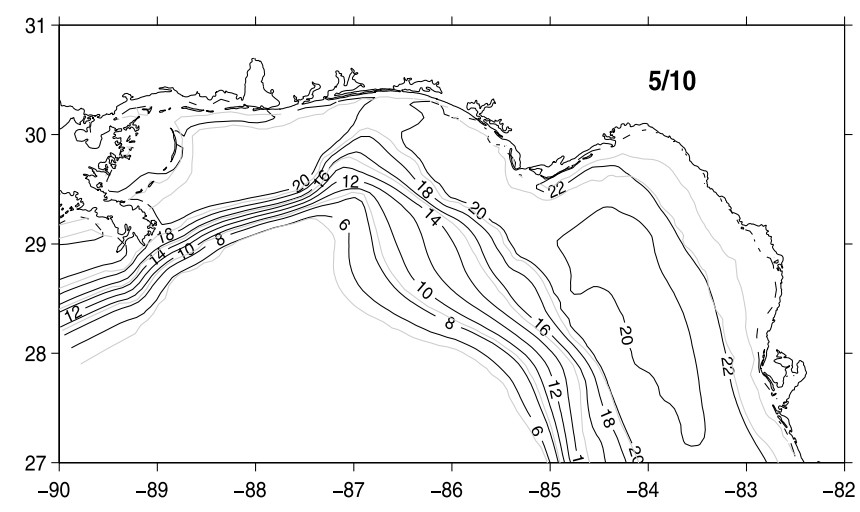

Figure 11. Modeled bottom temperature field sampled on 10 May 1998 for the case of local forcing only.
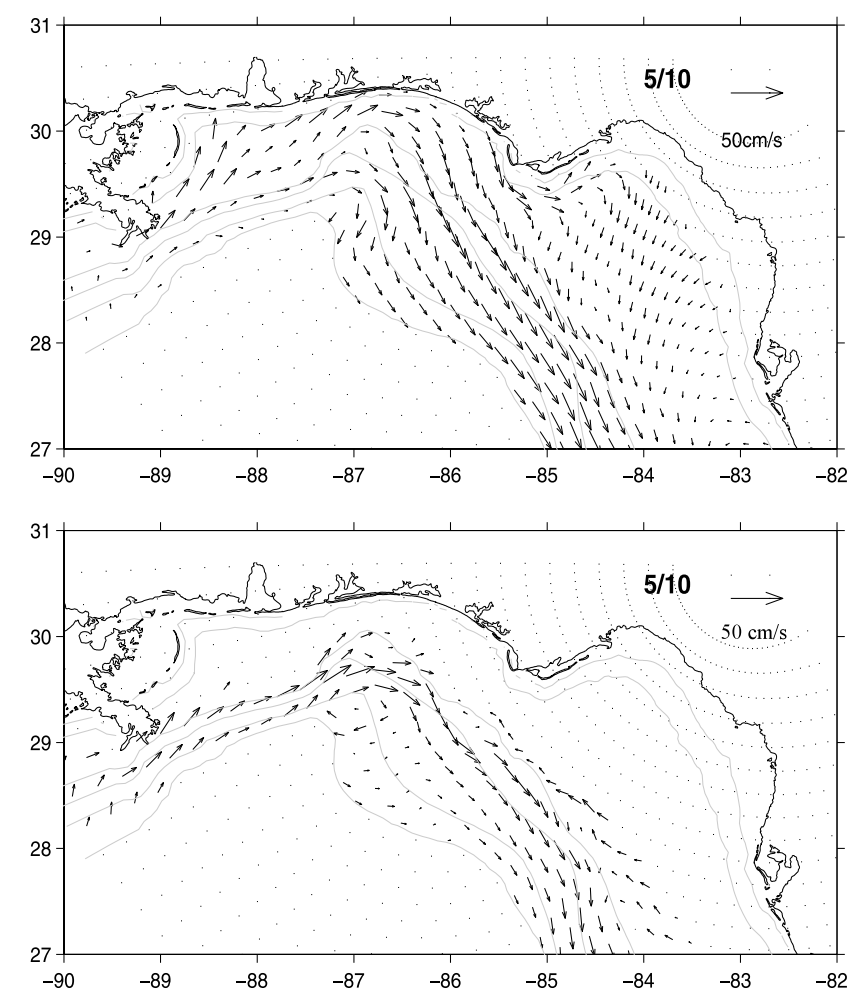

Figure 12. Modeled subsurface velocity fields at (top) $14 \mathrm{~m}$ depth and (bottom) $50 \mathrm{~m}$ depth sampled on 10 May 1998 for the case of local forcing only. 

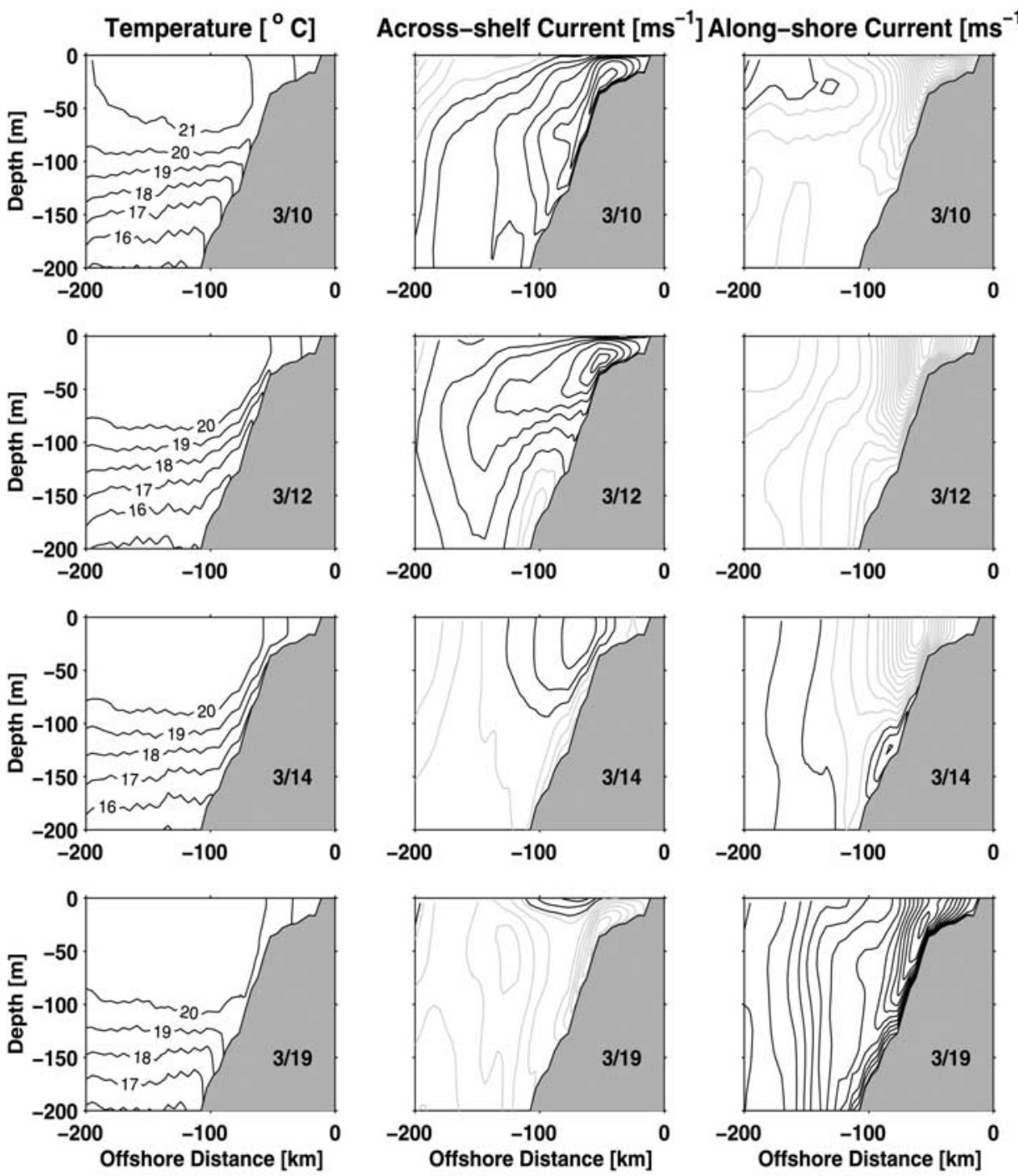

Figure 13. Across-shelf transects of the modeled temperature and across-shelf (u) and along-shelf (v) velocity components sampled at DeSoto Canyon on 10,12,14, and 19 March for the case of local forcing only. The contour interval on the velocity components is $0.02 \mathrm{~m} \mathrm{~s}^{-1}$; black lines denote onshore and westward flows; and gray lines denote offshore and eastward flows.

height along the open boundary in the south to allow for inflows and outflows consistent with the T/P data. The mode splitting solution of the POM facilitates rapid baroclinic adjustment at the open boundary since all of the vertically integrated transport must be in the external mode. Thus relatively stronger (weaker) currents exist above (below) the shallow thermocline. The model interior solution freely evolves in response to these fully baroclinic pressure and current fields imposed at the open boundary, and the interior adjustment is also rapid. With celerity of order $\mathrm{m} \mathrm{s}^{-1}$ the gravest baroclinic coastally trapped waves traverse the model domain from the Florida Keys to the Mississippi River (about $1000 \mathrm{~km}$ ) in about 10 days, a period comparable to the $\mathrm{T} / \mathrm{P}$ repeat interval.

[24] The controlling factors in our LC experiments are: 1) the imposed height field amplitude, 2) the location and width of the inflow-outflow window, and 3) time dependence. Several experiments were performed varying these factors to arrive at a solution sufficient to describe the observations. We settled on a time-independent, Gaussianshaped perturbation of magnitude $0.075 \mathrm{~m}$ applied over 17 grid points west of the Florida Keys (Figure 16) to mimic an impact at the shelf break by the outer edge of the LC. Given the $\mathrm{T} / \mathrm{P}$ repeat interval and smoothing limitations, finer tuning is neither justified, nor necessary.

\subsection{Results}

[25] Adding the LC modifies the modeled end of spring (Figure 7) states relative to the case of local forcing only. The currents are more coherently developed over the entire shelf, the nearshore SST is cooler, and the SSS core is positioned closer to the coast by virtue of the shoreward shifted current distribution. SSS is also lower over the shelf do to increased advection. How this occurs is evident near the LC impact window. A high-pressure perturbation propagates along the shelf slope from the point of impact which 

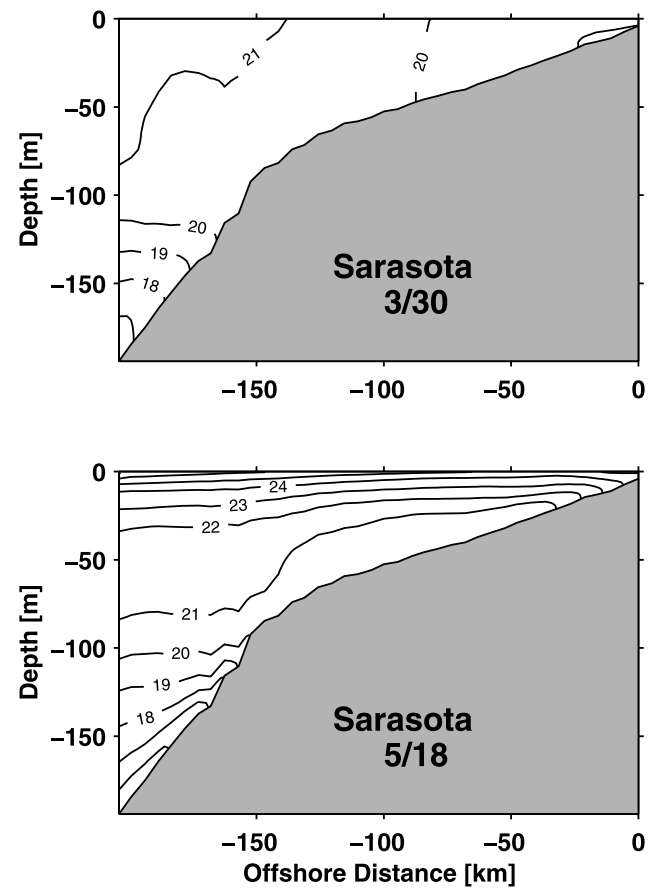

Figure 14. Modeled temperatures along the Sarasota transect sampled on 30 March 1998 and 18 May 1998 for the case of local forcing only.
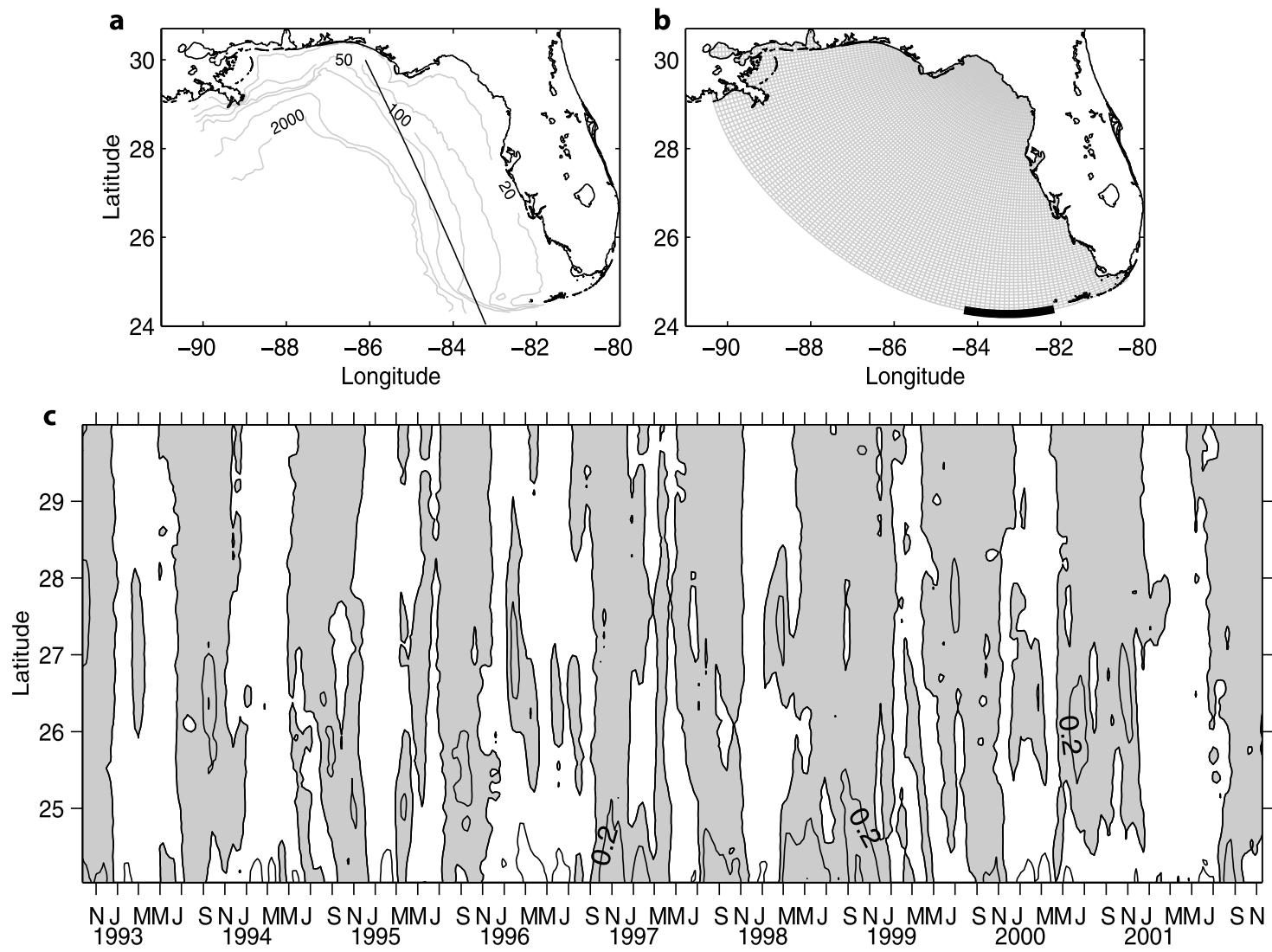

Figure 15. (c) TOPEX/Poseidon sea surface height anomalies from November 1992 to November 2001 sampled along track 26. Shading denotes positive anomalies. (b) The model domain open boundary control window (heavy line) along which we impose a sea surface height perturbation. 
causes northward flow to the west and southward flow to the east of the shelf slope [also see Hetland et al., 2001].

[26] Adding the LC also improves the fidelity between the modeled and observed currents, particularly at the $50 \mathrm{~m}$ isobath (Figure 8b). The current speeds are in better agreement near the surface relative to the local forcing only case (Figure 8a) and the unidirectional tendency of the currents also agrees now at depth.

[27] At the $20 \mathrm{~m}$ isobath (Figure 9b) the modeled currents are improved over the initial portion of record, but less dramatically so when compared with the $50 \mathrm{~m}$ isobath currents. The $20 \mathrm{~m}$ isobath currents remain largely locally forced with only a small increase in southward tendency. Over the latter portion of the record the solution under local forcing only (Figure 9a) looks better than the solution with the LC. The explanation resides in the density field where we see an extremis in the thermocline height located between the 50 and $20 \mathrm{~m}$ isobaths. The reversal in the thermocline slope across the extremis accounts for the different behaviors at these two isobaths. This convex thermocline shape is an important aspect of the shelf response because the sign of the thermal wind contribution to the baroclinic portion of the circulation reverses across it.

[28] The $30 \mathrm{~m}$ isobath location in the Panhandle shows minimal change in the modeled currents with the LC added (Figure 10b compared to Figure 10a). The anomalous unidirectional currents at this location are primarily locally forced. Nevertheless, the LC remotely incident on the southwest corner of the WFS still plays an important role in the Panhandle and (by connection) over the entire shelf. It does this by increasing the isotherm (or any material isoline) slopes at the shelf break, thereby increasing the potential for deep-ocean water to be upwelled onto the shelf by local forcing.

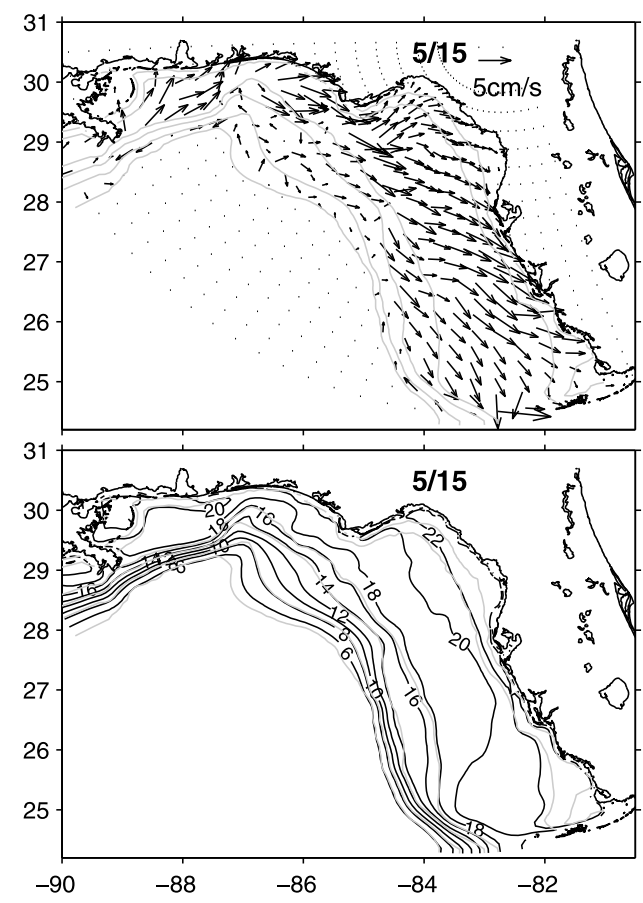

Figure 17. Modeled bottom velocity and temperature fields sampled on 15 May 1998 for the case of local plus Loop Current forcing.

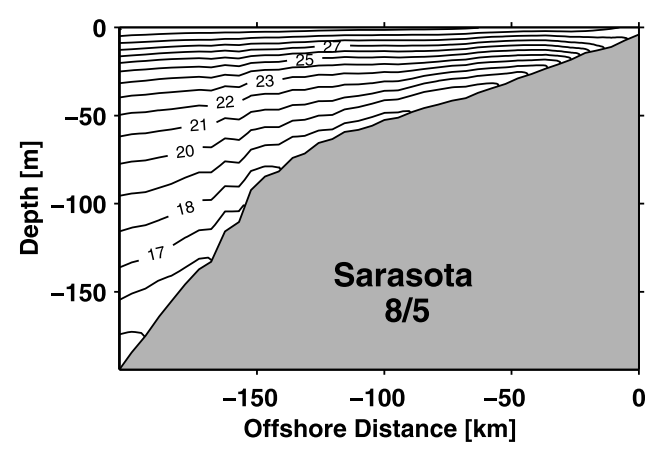

Figure 18. Modeled temperature sampled at the Sarasota transect on 5 August 1998 for the case of local plus Loop Current forcing.

[29] The upwelling/downwelling sequence beginning on 10 March (Figure 14 for local forcing only) proceeds very similarly with the LC added, but the water that is upwelled onto the shelf is about $1^{\circ} \mathrm{C}$ colder. By 14 March the entire DeSoto Canyon shelf is in the range of $17^{\circ}-18^{\circ} \mathrm{C}$ and waters of $16^{\circ}-17^{\circ} \mathrm{C}$ are broaching the shelf break. The ascent of these waters from their initial state is about $100 \mathrm{~m}$. Waters of $17^{\circ}-18^{\circ} \mathrm{C}$ also erupt to the surface in the Big Bend, independent of the DeSoto Canyon. Since the shelf break is about $20 \mathrm{~m}$ deeper at the Big Bend than at DeSoto Canyon less upwelling is required for an isotherm to broach the Big Bend shelf break (HW02). Each of the successive March frontal passages results in similar upwellings of deep-ocean water such that vertical stratification is established on the WFS by 30 March. April shows two major upwellings culminating on the 12th and the 24th, and since the net surface heat flux is into the ocean during these events all of the cold water, either modeled or observed, comes from depth. May is a month of nearly continuous upwelling, hence increasing vertical stratification as upwelling (surface heat flux) cools (warms) the water below (above) the thermocline. Figure 16 gives a 15 May example where we see $18^{\circ}-19^{\circ} \mathrm{C}$ waters in the Big Bend and a welldefined thermocline offshore of Sarasota (as in Figure 4). The Big Bend also appears to be a source of cold water for points farther south as seen in the 15 May near bottom temperature and velocity fields of Figure 17. Bottom temperature is in quantitative agreement with the NEGOM hydrography, and the bottom Ekman layer provides the means for across-shelf transport.

[30] Upwelling circulation persists through June causing the thermocline to sharpen. Persistent eastward flow across DeSoto Canyon also generates a semipermanent eddy that straddles the right angle bend in topography there. The upwelling circulation tendency tapers off in mid-July with the winds, but stratified conditions persist, do in part to the LC influence. By August, both the model (Figure 18) and the observations (Figure 5) at the Sarasota transect show similar patterns and magnitudes.

\section{Discussion}

[31] Whereas the Hetland et al. [1999] hypothesis derives from a barotropic model, our flow fields also have a baroclinic component, and these findings are compatible. 

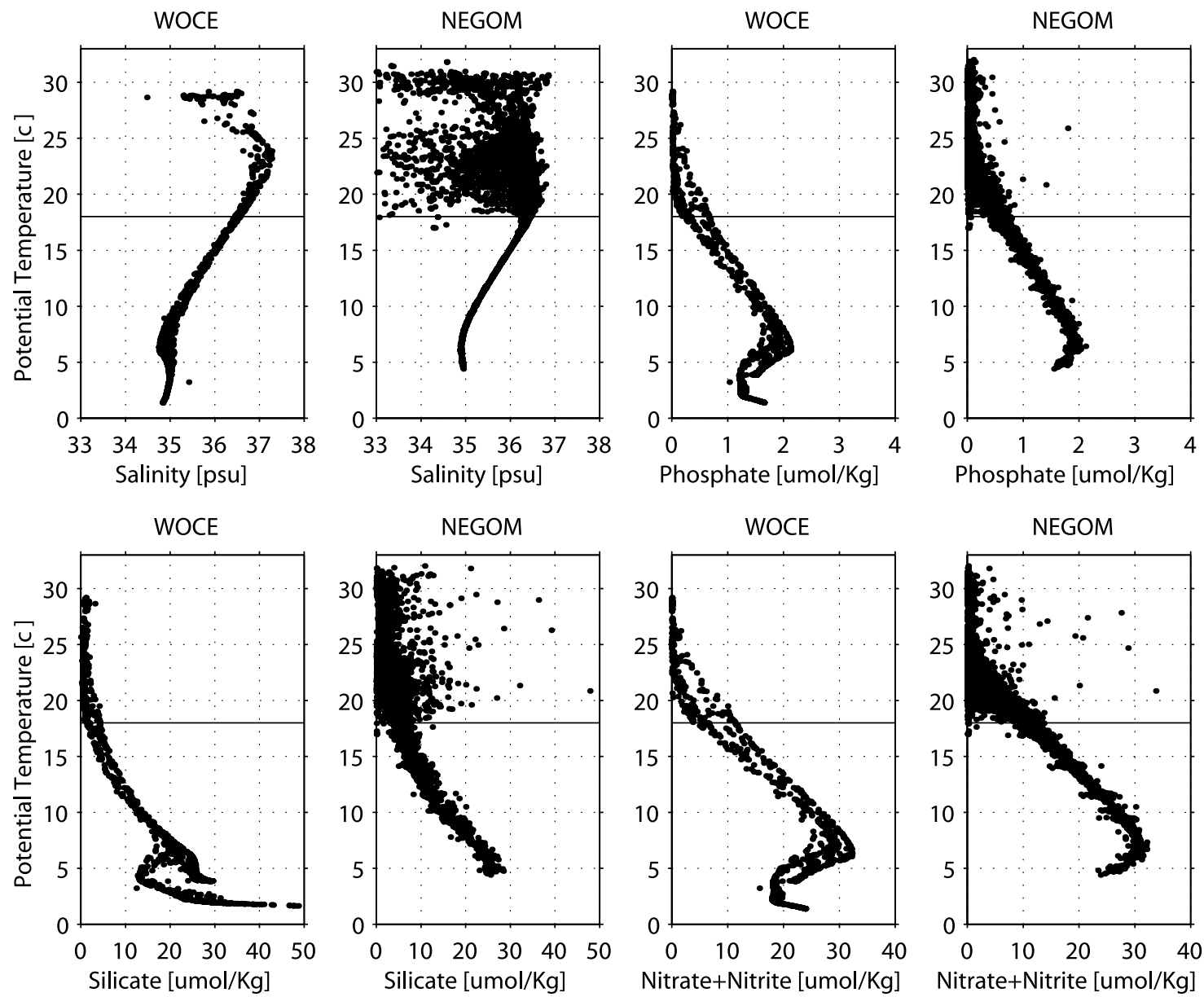

Figure 19. Temperature/salinity, temperature/phosphate, temperature/silicate, and temperature/(nitrate + nitrite) relationships from both the WOCE hydrographic section A22 subsampled between latitudes $11^{\circ}$ and $25^{\circ} \mathrm{N}$ and the NEGOM hydrographic survey.

Deep-ocean processes set the height of material isopleths at the shelf slope from which they may be upwelled onto the shelf by local forcing. Deep-ocean processes include the LC, either directly, or indirectly. The LC effect in 1998 is indirect. By impacting the shelf break in the southwest corner the LC sets shelf currents in motion from the point of impact to the Mississippi River Delta, consistent with the cyclonic propagation of coastally trapped waves [e.g., Gill, 1982, pp. 408-420]. The ensuing southward currents with sloping isopycnals along the shelf slope result in elevated material property isopleths that require less upwelling to broach the shelf break. Thus remote impact in the south facilitates increased cold water intrusion by local forcing in the north. Once on the shelf upwelled cold water conspires with surface heat flux to form a sharp thermocline that persists into summer. These factors also result in a convex thermocline shape, which is the basis for the observed and modeled baroclinicity. Since the thermal wind shear reverses across the thermocline apex the baroclinic and barotropic portions of the circulation may add constructively or destructively, explaining why the observed and modeled currents at the 50 and $20 \mathrm{~m}$ isobaths behave differently. Such spring-summer behavior also occurs in a normal year (HW02), but the LC can shift the thermocline apex depending upon which isobaths are impacted. A landward shift increases the temperature at the shelf break, and conversely, and this is one reason why replicating the observations is difficult. It is also why further tinkering with the open boundary condition is unwarranted since neither the spatial nor temporal variations of the LC impact can be determined well enough from the T/P data.

[32] The nutrients beneath the thermocline apex result from a mixture of deep-ocean and estuarine sources. Interannual variations in source water mixture results in interannual variations in shelf ecology. The deep-ocean source is readily explained on the basis of temperature/nutrient relationships. These are shown for the source waters of the Gulf of Mexico in Figure 19 using data from the WOCE section A22 subsampled between $11^{\circ} \mathrm{N}$ and $25^{\circ} \mathrm{N}$. Waters of temperature below $18^{\circ} \mathrm{C}$ show increasing nutrient levels at Redfield ratio that distinguish these from waters manufactured on the shelf by surface fluxes, land drainage, and utilization. These differences above $18^{\circ} \mathrm{C}$ are evident by comparing the WOCE and NEGOM hydrography (also in Figure 19). Using the NEGOM data, Walsh et al. [2003] compares the 1999 and 1998 nutrient distributions on the WFS. In 1999 the deep-ocean nutrient isolines are colinear with the isobaths and are located below the shelf break, whereas in 1998 these isolines cross isobaths and high values are found on the shelf, mimicking the Figure 11 
bottom temperatures. Recalling that the bottom temperature differences between our sections 3 (local forcing) and 4 (local forcing, plus LC) are only about $1^{\circ} \mathrm{C}$, we conclude that nutrient-rich waters would have upwelled onto the shelf in 1998 with or without the LC. The LC simply raised the nutrient levels a little higher.

[33] How nutrient rich water transits the shelf requires that we consider Lagrangian pathways. Synoptic wind forcing alone yields advective length scales of order tens of $\mathrm{km}$ [Weisberg et al., 1996]. Longer displacements require more persistent currents. At the $50 \mathrm{~m}$ isobath location, local forcing does produce persistent model currents, but only near the surface (Figure 8a). Near-bottom, where higher nutrient concentrations exist, persistent model currents require the LC (Figure 8b). Modeled and observed progressive vector diagrams (PVD) emanating from the $50 \mathrm{~m}$ isobath for 1 March to 31 August 1998 are shown in Figure 20. Under local plus LC forcing the near-surface displacements are in quantitative agreement and the middepth and near-bottom displacements are underestimated by about a third. PVDs are unrealistic for long integrations, however, since they assume no along-track velocity variation. This can be remedied in the model by calculating Lagrangian trajectories, as shown in Figure 21 for neutral particles released within about $1 \mathrm{~m}$ of the bottom (sigma layer 18) along the 20,50, and $100 \mathrm{~m}$ isobaths and tracked for 3 months. The trajectories that feed the inner shelf between Tampa Bay and Charlotte Harbor originate in the Big Bend, consistent with the near-bottom currents of Figure 17. This bottom Ekman layer conduit contains the coldest water formed through a mixture of upwelled deep water and surface-cooled shallow water. How the nutrients and phytoplankton vary en route under changing light conditions are the subjects of Walsh et al. [2003].

\section{Summary and Conclusions}

[34] We consider the question of local versus deep-ocean forcing in determining continental shelf water properties. The WFS, with narrow and wide regions and an adjacent boundary current, provides an excellent natural laboratory in which to address this question. We find that while deepocean processes set the depths of material isopleths along the shelf slope, local forcing is generally necessary to upwell materials across the shelf break. Once on the shelf local forcing is also the motive agent for distribution from the shelf break and the inner shelf with the bottom Ekman layer playing a major role. Deep-ocean effects under special circumstances may augment the distribution by local forcing, as occurred during the spring-fall seasons of 1998 (and also inferred in 1997).

[35] The spring transition generally features a midshelf cold tongue that extends southward from Cape San Blas. Seaward of the cold tongue core are regions of low salinity and elevated ocean color that are explainable on the basis of local wind and heat flux forcing, independent of the LC (HW02). The cold tongue persists subsurface into summer after the surface layer is paved over by heating. Since the cold tongue water is a mixture of deep-ocean and nearshore sources the nutrient content and hence the ecology of the WFS depends on these source water proportions. 1998 is anomalous in that the cold tongue is colder, longer lasting,

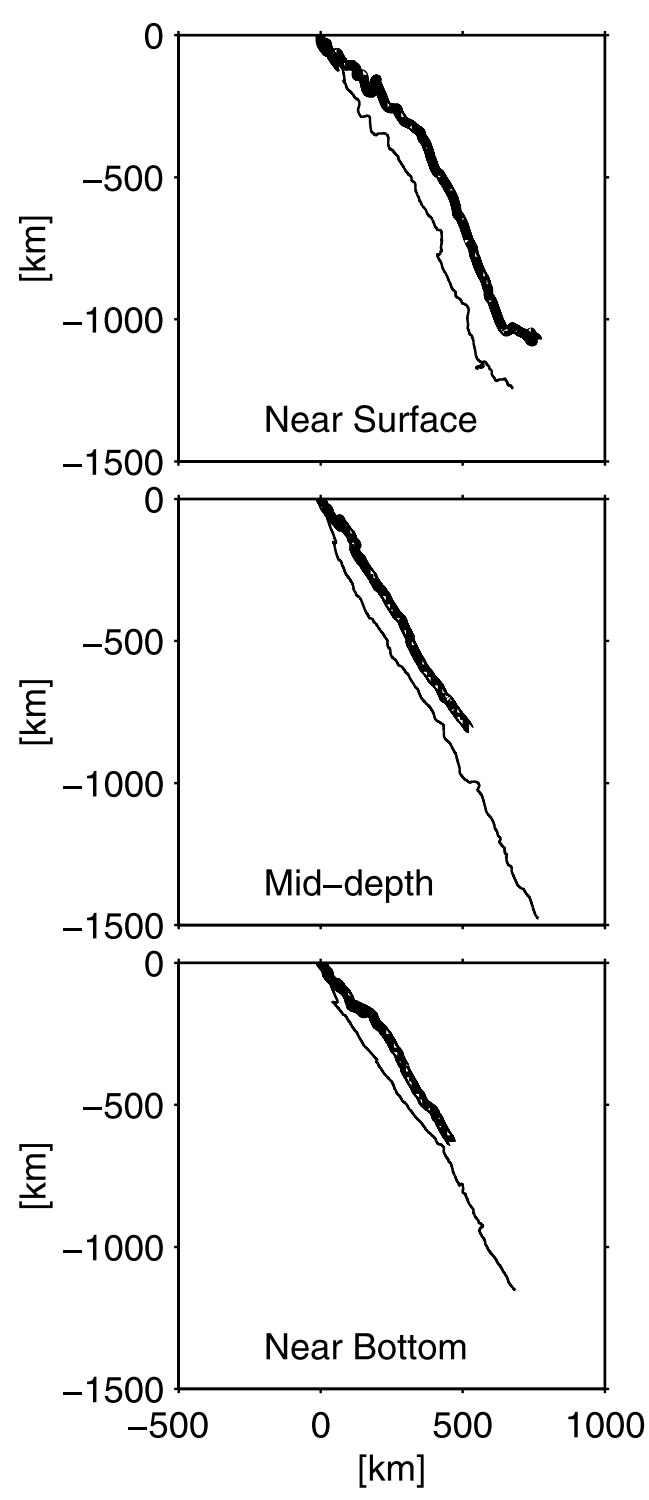

Figure 20. Progressive vector diagram comparisons between observed (thin lines) and modeled (thick lines) currents at the $50 \mathrm{~m}$ isobath (AS1/CM2) from March through August 1998 for the case of local plus Loop Current forcing. From top to bottom are the near-surface, middepth, and near-bottom results, respectively.

has elevated nutrients, and the thermocline is more sharply defined. We account for these observations by a combination of anomalous local forcing and anomalous LC influence. Local forcing alone accounts for anomalous upwelling, particularly over the Florida Panhandle. The LC adds to this by elevating material isopleths on the shelf slope, thereby allowing somewhat colder/higher nutrient concentration water to upwell across the shelf break.

[36] The LC influence is indirect, occurring remotely through shelf break impact west of the Dry Tortugas. By contacting relatively shallow isobaths the LC sets persistent southward currents in motion that facilitate the transport of waters upwelled farther north (DeSoto Canyon to the Big Bend) to inner shelf locations between Tampa Bay and Charlotte Harbor. While our results confirm the Hetland et 


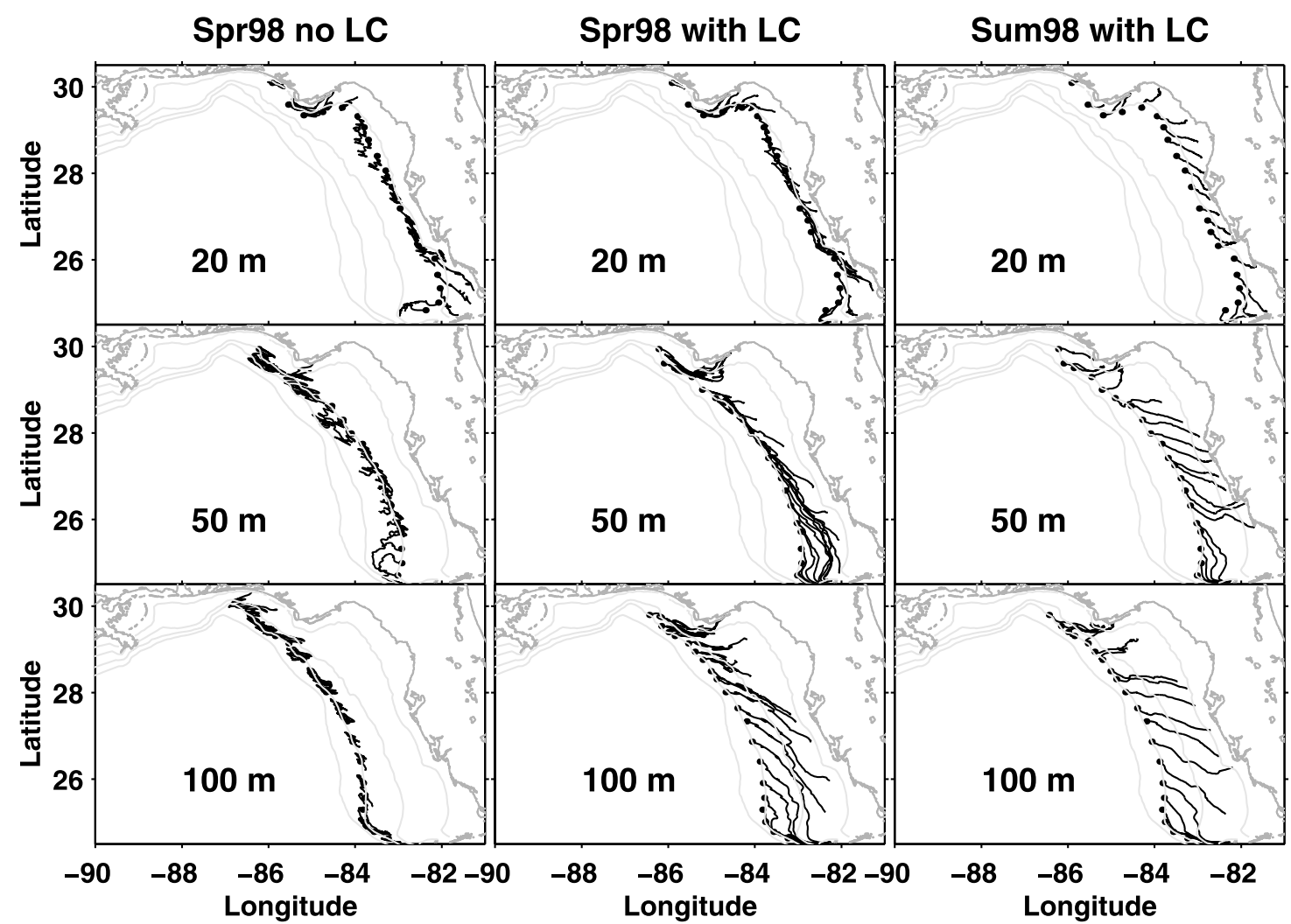

Figure 21. Modeled Lagrangian trajectories for neutrally buoyant particles released near the bottom along the 20,50, and $100 \mathrm{~m}$ isobaths (left) on 1 March 1998 under the influence of local forcing only, (middle) on 1 March 1998 under the influence of local plus Loop Current forcing, and (right) on 1 June under the influence of local plus Loop Current forcing. Tracking in all three cases is for 3 months.

al. [1999] barotropic theory, the transport mechanisms, being fully three-dimensional, are more complex. Local wind and heat flux forcing, irrespective of the LC, results in a convex thermocline shape that encompasses the subsurface cold tongue. The LC increases the sharpness of the thermocline (colder water upwells) and causes the thermocline apex to sidle landward, thereby modifying the baroclinic portion of the circulation. Oppositely sloping isopycnals on either side of the thermocline apex may enhance (mitigate) the LC influence on the currents seaward (landward) of the apex by thermal wind effects. At the apex, where the isotherms are flat, the currents are mainly barotropic. This explains why comparisons between our modeled and observed currents are improved upon LC addition more so at the $50 \mathrm{~m}$ isobath than at the $20 \mathrm{~m}$ isobath and why the currents at these two locations may flow in opposite directions. Moreover, by increasing the midshelf currents, the LC also increases the across-shelf transport of the bottom Ekman layer.

[37] The 10-year T/P record shows southwest corner LC impacts to be sporadic, having occurred in fall/winter 1996/ 1997, summer 1997, and as described here for 1998. Our 20 $m$ isobath measurements also show the 1996/1997 effects. LC impacts occurring farther north [e.g., He and Weisberg, $2003 \mathrm{~b}$ ] do not have as marked affect on the WFS because only deep isobaths are influenced. Nevertheless, material isopleths are raised in a cyclonic direction along the shelf slope helping to facilitate upwelling over the shelf break by local forcing. When this occurs the WFS receives deepwater nutrient injections that fuel interannual variations in shelf ecology.

[38] Our findings bear upon how to monitor a continental shelf. The bottom Ekman layer, being a conduit for acrossshelf transport, requires velocity and water property measurements. Measurements are also required at the shelf break because deep-ocean properties must first broach the shelf break in order to be transported across the shelf. A moored array that emphasizes the shelf break, the midshelf, and the nearshore regions (bracketing the thermocline apex and including nearshore salinity gradient regions by estuarine discharge) would provide part of a multifaceted monitoring program. Such program would also include radars for surface currents, autonomous profilers for water property fields, meteorological and sea level stations, and all available satellite products.

[39] In summary, we addressed the relative importance of local versus deep-ocean forcing of the WFS circulation through a coordinated program of in situ measurements and models. In general local forcing is primary and deep-ocean forcing is secondary. However, 1998 was anomalous for both local and deep-ocean forcing, and we investigated how these influences conspired to alter WFS water properties.

[40] Acknowledgments. Present support is by the Office of Naval Research, Grant N00014-98-1-0158; the National Oceanic and Atmospheric Administration, Grant NA76RG0463; and the State of Florida. Previous 
support was by the USGS, MMS, and ONR. R. He received of an endowed fellowship from the family of Elsie and William Knight. R. Cole managed our mooring operations. C. Merz provided a systems engineering overview and real time data capabilities (with R. Russell). J. Donovan assisted in all aspects of data acquisition, management, and computer systems. Data sets were kindly shared by many: W. Sturges (Florida State University) Panama City velocity data; G. Mitchum and B.G. Hong - T/P analyses; F. Muller-Karger - satellite SST; G. Vargo and C. Heil - USF hydrography; G. Kirkpatrick (Mote Marine Lab) - MML hydrography; W. Nowlin, A. Jochens, M. Howard, and S. DiMarco (Texas A\&M University) - NEGOM ship survey data; NOAA-CIRES Climate Diagnostics Center, Boulder CO NCEP reanalysis fields. We are particular grateful for the many stimulating discussions provided by $\mathrm{J}$. Walsh. This is ECOHAB contribution number 56.

\section{References}

Baumgartner, M. F., and S. P. Anderson, Evaluation of NCEP regional numerical predication model: Surface fields over the middle Atlantic Bight, J. Geophys. Res., 104, 18,141-18,158, 1999.

Blumberg, A. F., and G. L. Mellor, A description of a three-dimensional coastal ocean circulation model, in Three-Dimensional Coastal Ocean Models, Coastal Estuarine Sci., vol. 4, edited by N. Heaps, pp. $208-$ 233, AGU, Washington, D. C., 1987.

Boicourt, W. C., W. J. Wiseman Jr., A. Valle-Levinson, and L. P. Atkinson, Continental shelf of the southeastern United States and the Gulf of Mexico in the shadow of the western boundary current, in The Sea, vol. 11, edited by A. R. Robinson and K. H. Brink, pp. 135-182, John Wiley, New York, 1998.

Brink, K. H., Wind-driven currents over the continental shelf, in The Sea, vol. 10, edited by K. H. Brink and A. R. Robinson, pp. 3-20, John Wiley, New York, 1998a.

Brink, K. H., Deep-sea forcing and exchange processes, in The Sea, vol. 10, edited by K. H. Brink and A. R. Robinson, pp. 21-62, John Wiley, New York, 1998 b.

Chu, P., N. Edmons, and C. Fan, Dynamical mechanisms for the South China Sea seasonal circulation and thermohaline varibilities, J. Phys. Oceanogr., 29, 2971-2989, 1999.

Ezer, T., and G. Mellor, A numerical study of the variability and separation of the Gulf Stream, induced by surface atmospheric forcing and lateral boundary flow, J. Phys. Oceanogr., 22, 660-682, 1992.

Gill, A. E., Atmosphere-Ocean Dynamics, 408 pp., Academic, San Diego, Calif., 1982.

He, R., and R. H. Weisberg, West Florida Shelf circulation and temperature budget for the 1999 spring transition, Cont. Shelf Res., 22, 719-748, $2002 \mathrm{a}$.

He, R., and R. H. Weisberg, Tides on the West Florida Shelf, J. Phys. Oceanogr., 32, 3455-3473, 2002 b.

He, R., and R. H. Weisberg, West Florida Shelf circulation and temperature budget for the 1998 fall transition, Cont. Shelf Res., 23, 777-800, 2003a.

He, R., and R. H. Weisberg, A Loop Current intrusion case study on the West Florida Shelf, J. Phys. Oceanogr., 33, 465-477, 2003 b.

Hetland, R. D., Y. Hsueh, R. R. Leben, and P. P. Niiler, A Loop Currentinduced jet along the edge of the West Florida Shelf, Geophys. Res. Lett., 26, 2239-2242, 1999.
Hetland, R. D., Y. Hsueh, and D. Yuan, On the decay of a baroclinic jet flowing along a continental slope, J. Geophys. Res., 106, 19,797-19,808, 2001.

Hill, A. E., Buoyant effects in coastal and shelf seas, in The Sea, vol. 10, edited by K. H. Brink and A. R. Robinson, pp. 21-62, John Wiley, New York, 1998.

Kourafalou, V. H., L. Y. Oey, J. D. Wang, and T. L. Lee, The fate of river discharge on the continental shelf: 1 . Modeling the river plume and the inner shelf coastal current, J. Geophys. Res., 101, 3415-3434, 1996.

Mellor, G. L., and T. Yamada, Development of a turbulence closure model for geophysical fluid problems, Rev. Geophys., 20, 851-875, 1982.

Meyers, S. D., E. M. Siegel, and R. H. Weisberg, Observations of currents on the west Florida shelf break, Geophys. Res. Lett., 28, 2037-2040, 2001.

Muller-Karger, F. E., The spring 1998 northeastern Gulf of Mexico (NEGOM) cold water event: Remote sensing evidence for upwelling and for eastward advection of Mississippi water (or: How an errant Loop Current anticyclone took the NEGOM for a spin), Gulf Mex. Sci., 18, 55-67, 2000.

Nowlin, W. D., A. E. Jochens, M. K. Howard, and S. F. DiMarco, Nearshore bottom properties over the northeast shelves of the Gulf of Mexico as observed during early May 1998, TAMU Oceanogr. Tech. Rep. 98-3-T, 60 pp., Dep. of Oceanogr., Tex. A\&M Univ., College Station, 1998.

Nowlin, W. D., A. E. Jochens, M. K. Howard, S. F. DiMarco, and W. W. Schroeder, Hydrographic properties and inferred circulation over the northeast shelves of the Gulf of Mexico during spring to midsummer of 1998, Gulf Mex. Sci., 18, 40-54, 2000.

Orlanski, I., A simple boundary condition for unbounded hyperbolic flows, J. Comput. Phys., 21, 251-269, 1976.

Smagorinsky, J., General circulation experiments with primitive equations. I. The basic experiments, Mon. Weather Rev., 91, 99-164, 1963.

Steidinger, K. A., G. A. Vargo, P. A. Tester, and C. R. Tomas, Bloom dynamics and physiology of Gymnodinium breve with emphasis on the Gulf of Mexico, in Physiological Ecology of Harmful Algal Blooms, edited by D. M. Anderson, A. D. Cembella, and G. M. Hallegraeff, pp. 135-153, Springer-Verlag, New York, 1998.

Sturges, W., and R. Leben, Frequency of ring separation from the Loop Current in the Gulf of Mexico: A revised estimate, J. Phys. Oceanogr., 20, 1814-1819, 2000.

Walsh, J. J., et al., Phytoplankton response to intrusions of slope water on the West Florida Shelf: Models and observations, J. Geophys. Res., 108, doi:10.1029/2002JC001406, in press, 2003.

Weisberg, R. H., B. D. Black, and H. Yang, Seasonal modulation of the west Florida continental shelf circulation, Geophys. Res. Lett., 23, $2247-$ 2250, 1996.

Weisberg, R. H., Z. Li, and F. E. Muller-Karger, West Florida Shelf response to local wind forcing: April 1998, J. Geophys. Res., 106, 31,239-31,262, 2001.

Yang, H., and R. H. Weisberg, Response of the West Florida Shelf circulation to climatological wind stress forcing, J. Geophys. Res., 104, 53015320, 1999.

R. He and R. H. Weisberg, College of Marine Science, University of South Florida, 140 7th Ave. South, St. Petersburg, FL 33701, USA. (weisberg@) marine.usf.edu) 